\title{
WORLD
}

RESOURCES

WORKING PAPER

\author{
I N S T I T UTE
}

\section{BUSINESS AIR TRAVEL AND CLIMATE: CHANGING BEHAVIORS BEFORE, DURING, AND BEYOND THE COVID-19 PANDEMIC}

\section{EXECUTIVE SUMMARY}

\section{Highlights}

Before the COVID-19 pandemic, demand for air travel had been growing at a rate that outpaced decarbonization efforts. Individuals and organizations were struggling to reduce air travel in an effort to limiting global temperature rise to $1.5^{\circ} \mathrm{C}$ above preindustrial levels.

- Results from World Resources Institute (WRI) indicate that COVID-19 travel restrictions were a transformative event that drastically changed not only its business travel behaviors, but its staff perceptions and reduction commitments as well.

- In surveys administered to WRI staff in July 2020, after the COVID-19 pandemic had taken hold, over 60 percent of respondents and 70 percent of the most frequent travelers report that virtual meetings are more feasible and effective than previously thought. Comparing pre-COVID surveys with post-COVID surveys reveals an 80 percent increase in staff reporting that reducing business travel is possible.

- Surveys also show an increase of nearly 50 percent in staff making a personal commitment to reduce business travel post-COVID, where 85 percent of all staff and 96 percent of the most frequent travelers made a commitment to post-pandemic travel reductions.

- COVID travel restrictions resulted in significant emissions, budgetary, and time savings. Moving to virtual meetings resulted in 2,200 fewer flights in 10 months, a 92 percent decrease compared to the same period in 2019, pre-pandemic. This reduction in
CONTENTS

Executive Summary ................................1

1. Introduction 3

2. Applying Behavioral Science to Understand Travel Behaviors and Encourage Behavior Change .........7

3. Research Overview and Questions: Exploring and Supporting Business Travel Reductions at WRI ..... 9

4. Enabling Environment-Sectoral and Collective Action ............................. 23

5. Conclusion ........................................ 25

Appendices.........................................26

Endnotes......................................... 39

References ........................................ 47

Acknowledgments.................................. 48

Working Papers contain preliminary research, analysis, findings, and recommendations. They are circulated to stimulate timely discussion and critical feedback, and to influence ongoing debate on emerging issues. Working Papers may eventually be published in another form and their content may be revised.

Suggested Citation: Hernandez, M., S. Xu, L. Toh, S. Attwood. "Business Air Travel and Climate: Changing Behaviors Before, During, and Beyond the COVID-19 Pandemic." Working Paper. Washington, DC: World Resources Institute. Available online at https://doi.org/10.46830/wriwp.20.00148. 
flights avoids 3,000 $\mathrm{mt} \mathrm{CO}_{2} \mathrm{e}$, US\$2.6 million in ticket expenses, and 11,000 hours in flight time for staff.

As vaccines become widely available and travel demand resumes, this paper considers how applied behavioral science can help translate recent perception and behavior changes into long-term organizational and sector-wide practices and policies that sustain strategic business air travel reductions.

\section{Background}

Air travel produces an increasing share of global carbon and greenhouse gas (GHG) emissions. If global air travel in 2018 were a country, it would have been the sixth largest $\mathrm{CO}_{2}$ emitter in the world, between Japan and Germany (UCS 2020), with emissions rising steadily. Before the COVID-19 pandemic, aviation emissions were projected to quadruple by 2050 from 2020 levels (ICAO 2019). The observed increase has been driven in large part by growth in consumer demand, with business travel making up roughly 10-12 percent of that demand. (Borko et al. 2020; Trondent Development Corp. 2019) If we are to meet Paris Agreement targets to limit global temperature increase to $1.5^{\circ} \mathrm{C}$ above pre-industrial levels, organizations must find effective ways to reduce business travel.

As vaccines become widely available and travel restrictions are lifted, demand will resume and aviation emissions may rebound. This is the moment for organizations to design business travel policies and interventions that meet organizational objectives while encouraging reductions in air travel that are better for the planet, for travelers' well-being, and for organizational budgets. These policies should be intentionally designed with equity in mind so that reduced air travel does not translate into reduced opportunities for groups that are traditionally marginalized in the workplace. Given that travel choices are influenced not only by external factors (policies, costs) but by social and psychological factors like perceptions and social norms, insights from behavioral science can inform policies and programs aimed at sustaining recent travel reductions.

\section{About This Working Paper}

This paper explores the experiences and perspectives of staff at WRI, a global, environmental think-tank with over 1,40o staff working in 12 countries. From 2010 to 2019, WRI struggled with increasing emissions from air travel due to organizational growth, with its staff increasing by 4.8 times. Business travel produces roughly 30-40 percent of WRI's annual GHG emissions. In 2010, the organization committed to achieve a 20 percent absolute reduction of business travel emissions by 2020. To meet this ambitious target and design successful travel reduction policies, WRI sought to understand the barriers and context around business travel reductions for its staff. This paper summarizes insights from behavioral surveys conducted before COVID-19 (August 2019) and during COVID-19 (July 2020), allowing us to explore how employees' business travel perceptions, commitments, and behaviors changed over time.

The pandemic presented an opportunity to test whether people's perceptions of traveling changed after being forced to conduct all meetings virtually. We aim to understand how perceptions of business travel changed during the pandemic and whether changes in perceptions varied by demographic group, whether these changes translate into commitments to reduce future travel, and how insights from behavioral science can inform future workplace policies, procedures, and interventions that encourage staff to maintain low levels of air travel.

\section{Key Findings}

From March 2020 to December 2020, WRI cut almost all air travel, producing significant monetary, time, and emissions savings. The vast majority of would-be travelers reported that travel for in-person meetings had been effectively replaced by virtual meetings. Moreover, the vast majority of WRI staff report committing to reducing travel beyond COVID-19.

Administrative data showed that moving to virtual meetings in 2020 resulted in approximately 2,200 fewer flights from March to December 2020, compared to the same period a year earlier, equivalent to over $3,000 \mathrm{mt} \mathrm{CO}_{2}$ e or the additional carbon sequestered by 4,000 acres (over 2,000 soccer fields' worth) of U.S. forests in a year. Flight reductions also resulted in at least $\$ 2.6$ million in avoided ticket expenses and 11,00o hours in avoided flight time., ${ }^{1,2}$

Over 60 percent of survey respondents and 70 percent of the most frequent travelers report that virtual meetings are more feasible and effective than previously thought. Specifically, we find significant increases in staff perceptions that travel reduction is more possible, beneficial, and supported by their peers and supervisors than previously thought. Finally, 85 percent of all staff and 96 percent of 
the most frequent travelers made a commitment to postpandemic travel reductions.

\section{Virtual replacement opportunities are not cre-} ated equal: Some activities are thought to be more successfully replaced than others. A large proportion of respondents say that travel for project management, speaking engagements, and conference participation can be effectively replaced with virtual alternatives. Conversely, respondents report that travel for other activities like fund raising, relationship building, and data collection cannot be replaced as effectively.

\section{Organizations can leverage behavioral insights to design strategic travel-reduction policies that meet organizational objectives and improve} outcomes for the environment, staff, and budgets. Organizations can leverage the insights detailed in this working paper in several ways:

Make virtual easy: Invest in new virtual communications technologies, infrastructure, and training.

Use positive social norms and pledges: Design campaigns and interventions with behavioral insights in mind, such as public travel-reduction pledges and social norm messages that inform people about how their travel compares to their peers and to their own reduction commitments.

- Encourage senior staff to lead explicit travelreduction conversations: Senior staff can set influential norms by publicly committing to air-travel reductions and leading explicit travel-reduction planning conversations with staff.

Formalize institutional policies and procedures. Small changes can have outsized impacts: Small changes to budget templates or proposal guidelines can reflect institutional commitments to reduce travel.

To have a meaningful impact, the environmental sector should act in concert. Many survey respondents pointed out that WRI's efforts may be inconsequential without a sector-wide commitment to reducing air travel. Peer organizations, funders, and government and corporate partners should work together to change travel expectations, using virtual meetings whenever possible. Changes in donor reporting, virtual communications usage, and travel expenditures would provide evidence of wide-scale effects.
1 INTRODUCTION

\subsection{Air Travel Pre-COVID-19}

\section{An Upward Trajectory}

Before December 2019, commercial air travel and its corresponding emissions appeared to be marching steadily upward, with a 32 percent increase in global aviation emissions between 2013 and 2018 alone (El Takriti and Pavlenko 2017). Future projections were alarming: In 2015, the International Civil Aviation Organization (ICAO), the United Nations aviation body), estimated that airplane emissions of carbon dioxide would triple by 2050, growing from over 500 million metric tonnes in 2015 to over 1.5 billion metric tonnes (ICAO 2019).

So far, actual emissions surpassed projections. In 2018, emissions from global air travel totaled 918 million metric tons of $\mathrm{CO}_{2}, 1.7 \mathrm{x}$ higher than ICAO's 2015 projections (Graver et al. 2019). To put that in perspective, if global air travel in 2018 were a country, it would have been the sixth largest $\mathrm{CO}_{2}$ emitter in the world, between Japan and Germany (UCS 2020).

\section{Box 1| The 2015 Paris Agreement}

The Paris Agreement established global targets for reducing emissions and keeping the rise of global temperatures at bay. The agreement's objective is to keep global temperature rise to well below $2^{\circ} \mathrm{C}$ above pre-industrial levels and to pursue best efforts to limit this rise to $1.5^{\circ} \mathrm{C}$. Under the agreement, all countries commit to reducing national emissions as detailed in their respective Nationally Determined Contributions (NDCs). Today, even if countries deliver on pledges in their respective NDCs, some experts estimate that this will result in temperature increases of between $2.6^{\circ} \mathrm{C}$ and $3.9^{\circ} \mathrm{C}$ (Sherwood, et al. 2020).

Simply, we need to do more. It is possible that the global COVID-19 pandemic is a both a crisis and an opportunity to reimagine the way we live, work, and travel so that the ambitious targets laid out in the Paris Agreement can be met. 


\section{Air Travel as Contributor to Global $\mathrm{CO}_{2}$ Emissions}

The rise in air travel is critical because aviation is an underestimated contributor to global warming. Air travel's contribution is, in significant part, driven by increasing consumer demand that outpaces the industry's ability to decarbonize. Pre-COVID-19, passenger demand was increasing between 5 and 6 percent per year, while fleetwide fuel efficiency gains were only at 1 percent (Kharina and Rutherford 2015).

In wealthy countries, COVID-19 vaccines became widely available in 2021. Although the pandemic is surging in different regions, many governments have eased travel restrictions. Based on current flight increases, there is reason to assume that without intentional efforts, flight demand will resume (with wealthy nations driving the demand) and increase as projected (Figure 1). ${ }^{3}$ Therefore, if we are to meet Paris Agreement targets (Box 1) to limit global temperature increase to $1.5^{\circ} \mathrm{C}$ above pre-industrial levels, this is the moment for individuals and organizations to find effective ways to shift air travel behavior.

From a GHG emissions perspective, the aviation sector accounts for 1.9 percent of GHG emissions globally
(Ritchie 2020). But when looking only at $\mathrm{CO}_{2}$, the aviation sector's contribution is higher: approximately 2.5 percent of global emissions (Ritchie 2020). Further, there is a magnified warming impact from aviation emissions because soot and contrails are released into the upper atmosphere, increasing the impact on warming, an effect called radiative forcing (RF). When these additional impacts are considered, aviation may account for closer to 3.5 percent of global warming (Ritchie 2020).

Attempting to address aviation emissions through increased fuel efficiencies is an insufficient response: Aviation has not been able to identify pathways to decarbonize at levels significant enough to outpace the steady increase in demand. Thus far, fuel efficiency and the adoption of sustainable aviation fuel technologies that have managed to reduce emissions per mile have been outpaced by the growth in demand for air travel (Zheng et al. 2019).

Purchasing carbon offsets to balance out emissions produced would also be insufficient, especially when facing such rapid growth. ${ }^{4}$ Carbon offsets can be used to compensate for the high emissions impact of aviation by investing in other carbon-reduction projects, such as forest resto-

Figure 1 | Greenhouse Gas Emissions from International Aviation, 1990-2050 ( $\left(\mathrm{MTCO}_{2} \mathrm{e}\right)$

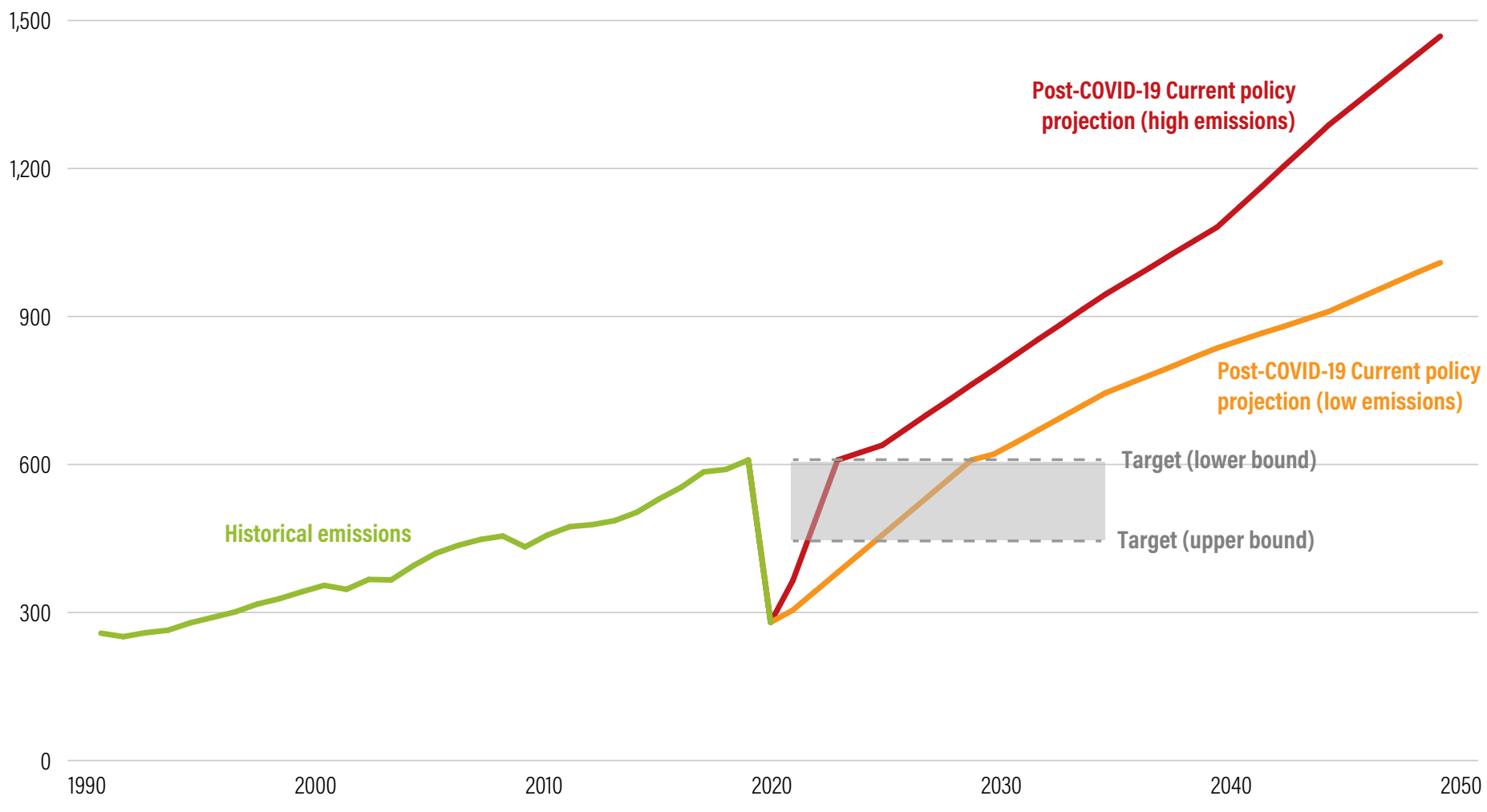

Source: Based on data from Climate Action Tracker (2020). 
ration. However, offsets do not necessarily incentivize organizations to avoid emissions at the source, missing the opportunity of cost-effective measures. While offsets can play a supporting role, larger emissions reductions at the source need to be made to achieve fast and significant decarbonization. ${ }^{5}$

Simply, we must address the underlying demand for air travel.

\section{Impacts of Business Travel}

Drawing on estimates that 10-12 percent of global airline passengers are business travelers (Borko et al. 2020;

Trondent Development Corp. 2019), the annual emissions from business travel may range from 74.7 to 89.6 million metric tons of $\mathrm{CO}_{2}$, equivalent to the emissions from 8.5 to 10 billion gallons of gasoline. ${ }^{6}$

Beyond climate, business travel affects organizations' budgets and travelers' quality of life. Employees who travel frequently experience travel fatigue, health problems, and strains on family and other personal relationships. Indeed, medical studies have linked long-haul travel to strokes, heart attacks, and deep-vein thrombosis as well as unhealthy diets, poor sleep, and mood swings. Even before the pandemic, frequent travelers faced the need to balance the expectations of the importance of business travel with its negative personal impacts. (Chamorro-Premuzic 2015) On the employer side, organizations could benefit

\section{Box 2 | World Resources Institute: A Growing Global Organization}

World Resources Institute (WRI) is a nonprofit organization whose mission is "to move human society to live in ways that protect Earth's environment and its capacity to provide for the needs and aspirations of current and future generations (WRI 2021)." A focus on environmental sustainability as an employer is increasingly critical as WRI grows as an organization.

As of November 2020, WRI had over 1,400 staff working in 8 global regions, including the United States, Africa, Brazil, China, Europe, India, Indonesia, and Mexico, and program offices in Colombia and Turkey.

financially from a reduction in business travel if its functions and productivity could be substituted effectively by other nontravel means. Industry data suggest that average U.S.-based business travel costs $\$ 111.7$ billion, and international travel costs $\$ 31.6$ billion a year (Certify 2021). Business travel represents the second-highest expenditure after payroll for mid-sized and large companies in the United States (Grous 2017).

WRI (Box 2) tracks business travel as a portion of the organization's total carbon footprint. ${ }^{7}$ While WRI's aviation-related emissions rates per person have declined over time, business travel still accounts for nearly a third of its total emissions (Figure 2).

Figure 2 | Greenhouse Gas Emissions from WRI's Business Air Travel, 2010-2019 (MT CO $\left.{ }_{2} \mathrm{e}\right)$

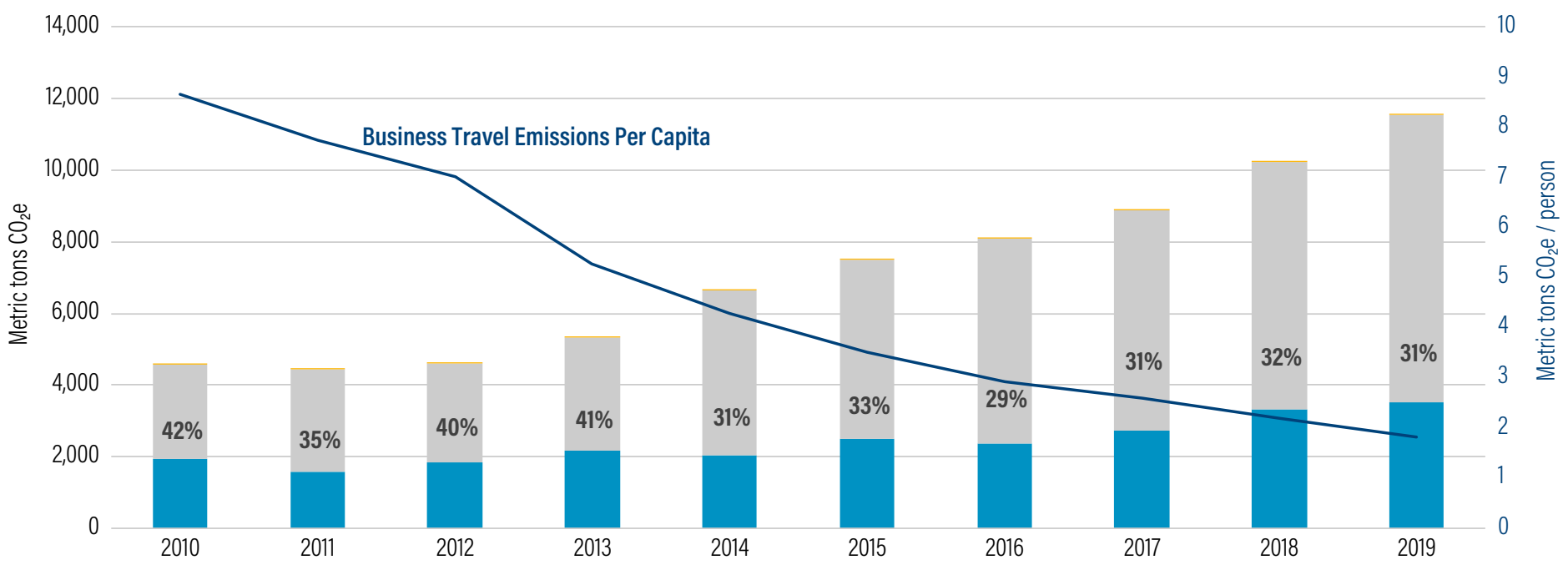

Source: WRI Authors.

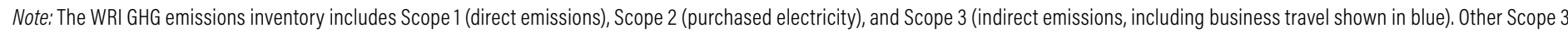
activities include emissions from goods and services, transmission losses, waste, and commuting. 
See Section 1.4 for more information on WRI's GHG reduction efforts.

Beyond the climate toll, the time lost and monetary costs of travel are clear at WRI. According to administrative data from WRI's booking system, ${ }^{8}$ WRI spent $\$ 3$ million in total, or nearly $\$ 2,800$ per person, on air travel in 2019, ${ }^{9}$ excluding lodging and per diem-related expenses. Over the same period, staff spent almost 20,000 hours in the air ${ }^{10}$ equivalent to every WRI staff member spending 4.5 workdays on an airplane. This figure balloons for frequent travelers: On average, the top 25 percent of travelers each spent 26.5 workdays on an airplane in 2019.

\subsection{Air Travel during COVID-19: A Catalyst for Behavior Change}

\section{Historical Reductions and Decreasing Emissions}

In response to the COVID-19 pandemic, governments and businesses around the world issued nonessential travel bans, transforming the choice to travel into an automatic default into virtual alternatives.

The grounding of planes en masse and corresponding shifts in travel behavior are unprecedented. Air travel has experienced declines after other health outbreaks (SARS) and crises (September 11th terrorist attacks), but COVID19 decreased air travel more dramatically and for a longer period of time than ever before (Borko et al. 2020).

International Air Transport Association (IATA) data show that in 2020, global air travel demand was 65.9 percent lower than in 2019 (IATA 2021). There is evidence that the post-pandemic changes in aviation daily activity and the corresponding decrease in $\mathrm{CO}_{2}$ emissions have been significant even when compared to other sectors including transportation, energy, and agriculture. ${ }^{11}$ From March to April 2020, there was a drastic 75 percent decrease in daily departing flights. As of July 2020, these decreases contributed 13 percent of the total decrease in global $\mathrm{CO}_{2}$ emissions since the COVID-19 pandemic began (Le Quéré et al. 2020; Liu et al. 2020). Flight decreases have been especially pronounced in the business travel sector. Corporate bookings fell by 85 percent in 2020 and remained low through the first quarter of 2021 (Stalnaker and Usman 2021).

\subsection{Air Travel Outlook: An Opportunity}

\section{Sustaining Behavior Change amid an Uncertain Future for Business Travel}

The outlook for business travel after COVID-19 is uncertain. Major airlines in the United States are predicting that business travel will quickly return to pre-pandemic levels, due to pent-up demand. However, industry analysts are forecasting a permanent reduction in business travel levels because companies have discovered that technology can be effectively used to conduct many types of meetings that were formerly in-person, such as intra-company training (McCartney 2020). A global survey of business travelers found that 43 percent of respondents expect to travel less post-pandemic, and 58 percent plan to continue videoconferencing as much as they have during the pandemic (Stalnaker and Usman 2021).

Returning to unsustainable levels of air travel is avoidable. Evidence from WRI's research indicates that leveraging technology, introducing supportive policies, and setting explicit pro-environmental norms can maintain pandemic-induced behavioral changes to keep business travel at sustainable levels.

The opportunity to transform the way we travel has the potential to pay dividends in improved health of the planet, organization's budgets, and people's time and quality of life. Using WRI as an illustrative example, between March and December 2020 the organization decreased flights by 92 percent, compared to the same period a year earlier (Figure 3). This reduction from the same period in 2019 to 2020 avoided over $3,000 \mathrm{mt} \mathrm{CO}_{2} \mathrm{e}$, the equivalent of the carbon sequestered by 4,000 acres of U.S. forest in a year. ${ }^{12}$ If WRI were to sustain just a third of these flight reductions after the pandemic-which is the average proportion of air travel that survey respondents say they are willing to reduce-it would save $\$ 1$ million in ticket costs alone and save almost 10,000 hours of staff time each year. 
Figure 3 | Money and Time Spent on Business Air Travel by WRI, 2019-2020 (Dollar's, Hours)

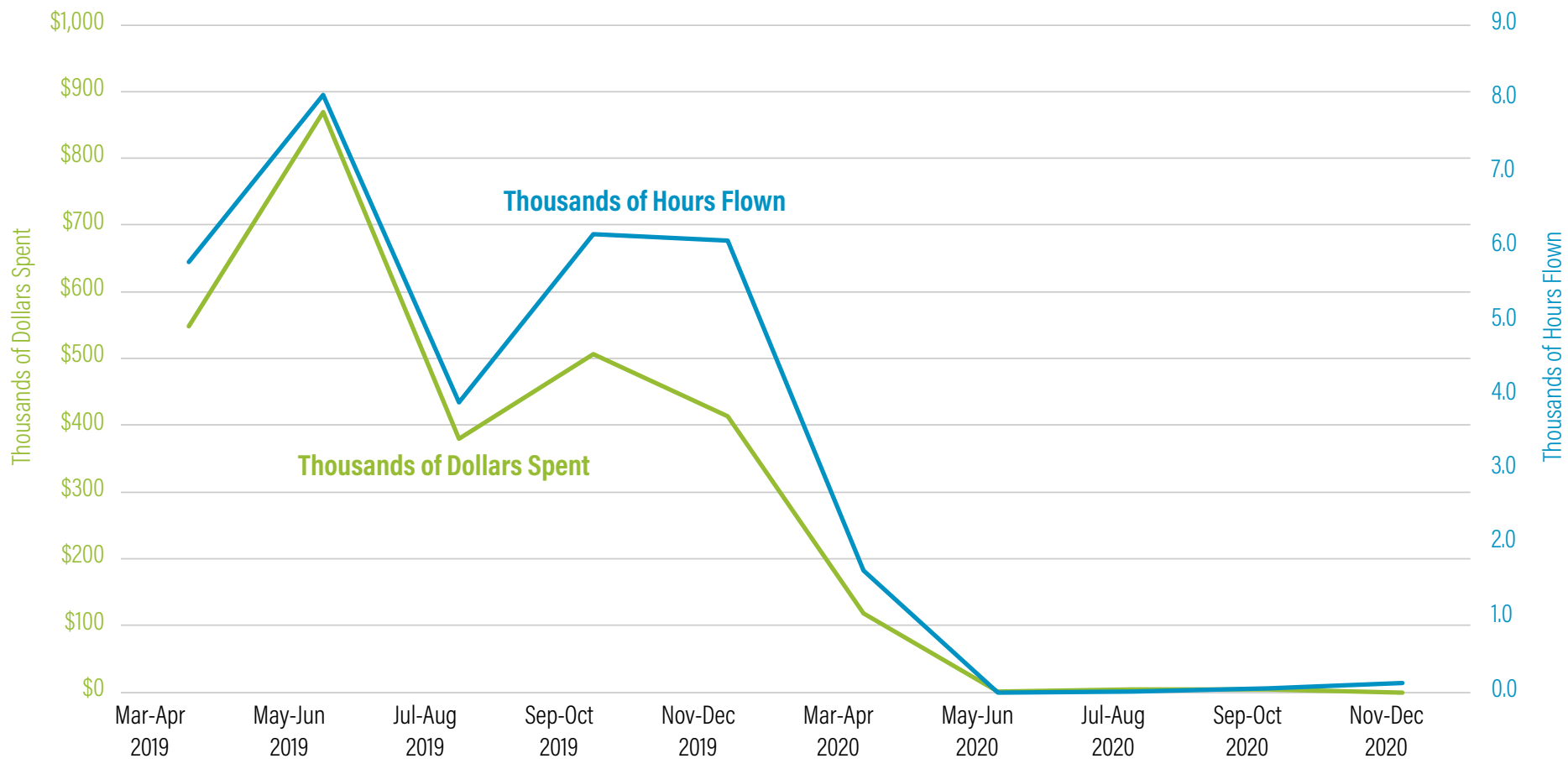

Source: WRI Authors.

\subsection{WRI's Internal Sustainability and Business Travel Reduction Efforts}

The organization has taken the opportunity to lead in sustainability, applying WRI research and data tools to reduce the organization's environmental impacts. WRI's Sustainability Initiative has conducted annual GHG emissions tracking and reporting since 2001. In 2010, WRI set science-based targets for its top three emitting activities, including a 20 percent reduction of emissions from business travel by $2020 .{ }^{13}$ By 2019 , absolute emissions from business travel had increased by 83 percent from 2010 levels due to institutional growth. In 2020, emissions fell by 57 percent from 2019 levels because all travel was halted halfway through the fiscal year due to the pandemic. This translates to a 22 percent reduction from 2010 levels, exceeding WRI's 20 percent reduction target. WRI would not have been able to meet this target without the COVID-19 travel restrictions.

To achieve targeted reductions in GHG emissions, the Sustainability Initiative has piloted a number of travel reduction initiatives. For example, travel data tracking has been part of WRI's sustainability efforts for the last 10 years.
As the 2020 GHG reduction targets deadline approached, the Sustainability Team has conducted surveys of staff to understand the intentions, barriers, and opportunities around air travel reduction.

After WRI imposed a ban on all nonessential travel on March 3, 2020, WRI revised the usual travel survey to capture the impacts of WRI's travel ban on staff. ${ }^{14}$ The survey and analysis were co-designed by WRI's behavioral science team and were informed by behavioral science research methods, which offer ways to identify barriers to behavior change as well as point to promising solutions.

\section{APPLYING BEHAVIORAL SCIENCE TO UNDERSTAND TRAVEL BEHAVIORS AND ENCOURAGE BEHAVIOR CHANGE}

\subsection{Behavioral Economics}

Behavioral economics is the study of how people make choices and draws on insights from both psychology and economics. Traditional economic models assume that people act rationally and pursue their goals consistently 
without the need for support. Applying a behavioral lens provides a fresh perspective.

\section{Bounded Rationality}

Bounded rationality is a foundational notion of behavioral economics and proposes that we are not the perfectly rational decision-makers presented in a standard economic model. Rather, our rationality is bounded by a tendency toward well-documented mental shortcuts or heuristics. For example, a rational actor model assumes that if people want to change and can change their behavior-to fly less frequently, for example-then behavior change will follow. However, decades of social science research have found evidence that invisible and often overlooked situational factors can have an outsized impact on our ability to close the gap between our intentions and actions, producing intention-action gaps (Sheeran 2005; Sheeran and Abraham 2003). ${ }^{15}$ These gaps are the spaces between our intentions to change and/or maintain a specific behavior and our actual follow-through; for example, our intentions to fly less and our actual flight patterns.

\section{Situationalism}

What explains the intention-action gap? We all face situations or decision-making environments that can be complicated. The social psychologist Kurt Lewin described these rich environments as "tension systems" with forces that pull us toward and away from certain behaviors (Lewin 1943). Forces propelling us toward a behavior are referred to as channel factors, situational details within our choice environments that affect behavior by providing critically placed psychological bridges from intention to action. (Think of the bright green recycling bins with a perfect can-shaped hole cut out, making the connection to recycling a soda very easy.) Barriers are the forces that pull people away from behaviors. ${ }^{16}$ For example, regardless of a stated institutional goal to decrease air travel, staff may sense that frequent flying is an unstated organizational status symbol, creating a barrier to reduced travel. Both real and perceived barriers influence our intentions and behaviors.

\section{The Unique Situation of COVID-19}

People often underestimate the impact of situational factors in determining behavior and perceptions. Unique events are instructive. As Ross and Nisbett eloquently point out in The Person and the Situation (1991), "In the course of ordinary experience, we rarely have the chance to observe the same people in radically different roles or situations.... [O]f course, we sometimes do get to see familiar people in novel situations; and on such occasions, especially when the new situation differs radically in its opportunities and constraints from the ones in which we've had occasion to observe the actor in the past, we are apt to be surprised and enlightened."

As this working paper details, COVID-19 reshaped the business travel tension system and provided the opportunity to observe familiar actors in a novel situation. As Ross and Nisbett predict, we find, via a sample of WRI employees, surprising and enlightening changes. The COVID19 pandemic and subsequent travel ban produced an expected plummet in business travel. But it also produced significant and largely positive changes in people's perceptions of travel reduction and increased intentions and commitments to reduce business travel in the future.

\subsection{Behavioral Design Process}

To design an effective policy or intervention aimed at changing behavior, behavioral scientists engage in a formative research process referred to as a behavioral design process. This process includes the following key steps:

1. DEFINE: As discussed earlier, behavioral science posits that the situation is a strong determinant in our behavior. Therefore, a critical first step is to identify and define the context and details in which people are making a decision.

2. DISCOVER: This phase of formative research uses qualitative and quantitative methods to unpack, understand, and quantify the aspects of the situation (or tension system) influencing people's choices. What are the specific barriers and channel factors, how are they perceived, and do those barriers influence different groups in unique ways?

3. DESIGN: With an understanding of the program's context and barriers, we target the gaps where people face unintended barriers and consider ways to design interventions, policies, or behavior change campaigns that decrease barriers and offer psychological subsidies like pledges or reminders. Ideally, the intervention has broad applicability for other organizations and contexts. 


\section{RESEARCH OVERVIEW AND QUESTIONS: EXPLORING AND SUPPORTING BUSINESS TRAVEL REDUCTIONS AT WRI}

Using the formative process detailed earlier, the research detailed in this working paper had the following objectives:

DEFINE the business travel challenge at WRI.

How were WRI staff traveling before COVID-19?

What was the frequency and purpose?

How did travel vary within the organization?

\section{DISCOVER barriers.}

Before COVID-19, what were the staff's perceptions of reducing business travel?

What barriers did staff face in replacing business travel with virtual or non-air travel, and did these barriers and perceptions influence people's travel intentions and behaviors?

What were the pain points, and what opportunities existed to reduce business travel?

DISCOVER opportunities.

How did COVID-19 change the staff's business travel behaviors?

What was the staff's perception of the effectiveness of virtual replacement, and did this vary within the organization?

- Did the post-COVID-19 experience with reduced travel influence perceptions of reducing business travel, and did this vary within the organization?

- Did the experience with reduced travel influence future intentions and commitments, and did this vary within the organization?

DESIGN. While this working paper does not include an intervention design, using the insights gleaned from the formative research process, we explore the implications for a future travel reduction intervention. Specifically, we aimed to understand

what the barriers and opportunities presented by sustained business travel reductions are and whether these vary within the organization; and

what behaviorally informed policies and programs would support staff in maintaining reduced business travel.

\subsection{Data Sources and Methods}

\section{Pre-COVID Survey $(\mathrm{N}=140)$}

On August 14, 2019, WRI's sustainability team sent a travel and commuting survey (pre-survey) to 368 staff who had booked flights using WRI's central travel booking system. ${ }^{17}$ We received 140 responses, representing a response rate of 38 percent. The original pre-survey can be found in Appendix A. In terms of representation, we see a slight over-indexing of WRI U.S. and mid-level staff. In addition, as the survey was not mandatory, responses were from those individuals who self-selected to give answers. These individuals may differ in important ways from nonresponders within the institute as the responders may have stronger opinions toward the issue of business travel. See the pre-survey response table in Appendix $\mathrm{C}$ for more detail.

The survey captured self-reported frequency of air travel, ${ }^{18}$ type of work that required the most air travel, perceptions of business travel, and challenges and opportunities to decrease air travel.

\section{Post-Initial Lockdowns Survey (N = 457)}

On June 23, 2020, almost six months into the COVID-19 pandemic and four months into WRI's travel ban, WRI's sustainability team sent the travel and commuting survey (post-survey) to all 1,322 staff and received 457 responses for a response rate of 35 percent. The original survey can be found in Appendix B. Note that because this survey asked potentially sensitive questions (for example, about how motivated or unmotivated staff were feeling while working from home), this survey was anonymous. Aside from a slight over-representation of mid-level staff, the sample was well-balanced on observable characteristics (across seniority levels, offices, and gender). See the postsurvey response table in Appendix D.

The goal of the post-survey was similar to the 2019 survey, but in addition we wanted to understand the amount of forgone travel, experiences and effectiveness of substituting air travel with virtual contacts, and changes in staff perception of the feasibility and subsequent change in intentions to substitute air travel post COVID-19. ${ }^{19}$

\section{Administrative Flight Data}

WRI's sustainability team has also collected data on flights taken by WRI staff since 2012. The data come from WRI's online booking system, through which all staff in WRI's U.S. and China offices have been required to book flights 
since 2018. Administrative flight data are only complete for U.S. and China staff. ${ }^{20}$

\section{Focus Group Discussions (FGDs) ( $\mathrm{N}=15)$}

A series of FGDs took place in December 2020. Participants represented six global offices; men and women; junior, mid-level, and senior staff; and both average and highest flying staff. The goal of the FGDs was to add qualitative insights to the survey findings and gather ideas on ways to effectively design policies that support travel reductions beyond COVID-19.

We use average-based change to evaluate the change in the distributions' center to survey responses and administrative flight data before COVID-19 restrictions and after. When stipulated, we use a statistical means tests to calculate the significance of the difference between the pre- and post-survey results.

\subsection{Results}

\subsubsection{Define: The Business Travel Challenge}

How were WRI staff traveling before COVID-19, and did travel vary within the organization?

Both the flight data and pre-pandemic survey data reveal that, pre-pandemic, the average WRI staff member traveled almost every other month, with the most frequent travelers being senior staff and staff in China, India, and Brazil. In terms of travel purpose, staff reported that the top reasons for travel included conference participation, relationship building, and conference management. We also found that men traveled significantly more frequently than women regardless of seniority level, office, and travel purpose, at almost three additional trips per year.

Pre-COVID-19 flight frequency (administrative data): From the flight data, we can see that U.S. and China staff took a total of 3,674 flights in fiscal year 2019, which pro- duced a total of 2243.8 MT of $\mathrm{CO}_{2}$ e emissions. Averages hide a great deal of variance. The frequency and impact of air travel varies most significantly by seniority level, as shown in Table 1. The average senior staff member traveled over three times as often as the average mid-level and junior staff member. ${ }^{21}$

Trip frequency (self-survey data): In addition to the administrative data, the pre- and post- surveys asked respondents to self-report on how many trips they had taken in the last 12 months. Self-reported data can be less precise than flight data, but the self-reported data captured data from all offices and therefore provides a more nuanced organization-wide view of travel behavior.

From the survey data, we see that staff report taking an average of six trips from March 2019 to March 2020. ${ }^{22}$ Mirroring the administrative data, flight behavior varies by seniority with senior staff taking an average of 12 trips each year, compared to an average of 5 for junior and midlevel staff (Figure 4).

\section{Table 1 | Flight Frequency of WRI U.S. and China Staff by Seniority, 2019 (Administrative Data)}

\begin{tabular}{l|r|r} 
N & $\begin{array}{r}\text { AVG. NO. OF FLIGHTS } \\
\text { PER PERSON }\end{array}$ & $\begin{array}{r}\text { GHG EMITTED PER } \\
\text { PERSON (MT CO } 2 \text { E) }\end{array}$ \\
\hline All staff $(\mathrm{N}=589)$ & 6 & 3.81 \\
\hline Senior $(\mathrm{N}=42)$ & 17 & 10.76 \\
\hline Mid-level $(\mathrm{N}=316)$ & 8 & 4.67 \\
\hline Junior $(\mathrm{N}=231)$ & 2 & 1.37
\end{tabular}

Note: GHG data use DEFRA emissions factors for 2019 with radiative forcing. For more detail on WRI GHG emissions calculations methods, see Methodology | World Resources Institute (wri. org).

Source: WRI Authors 


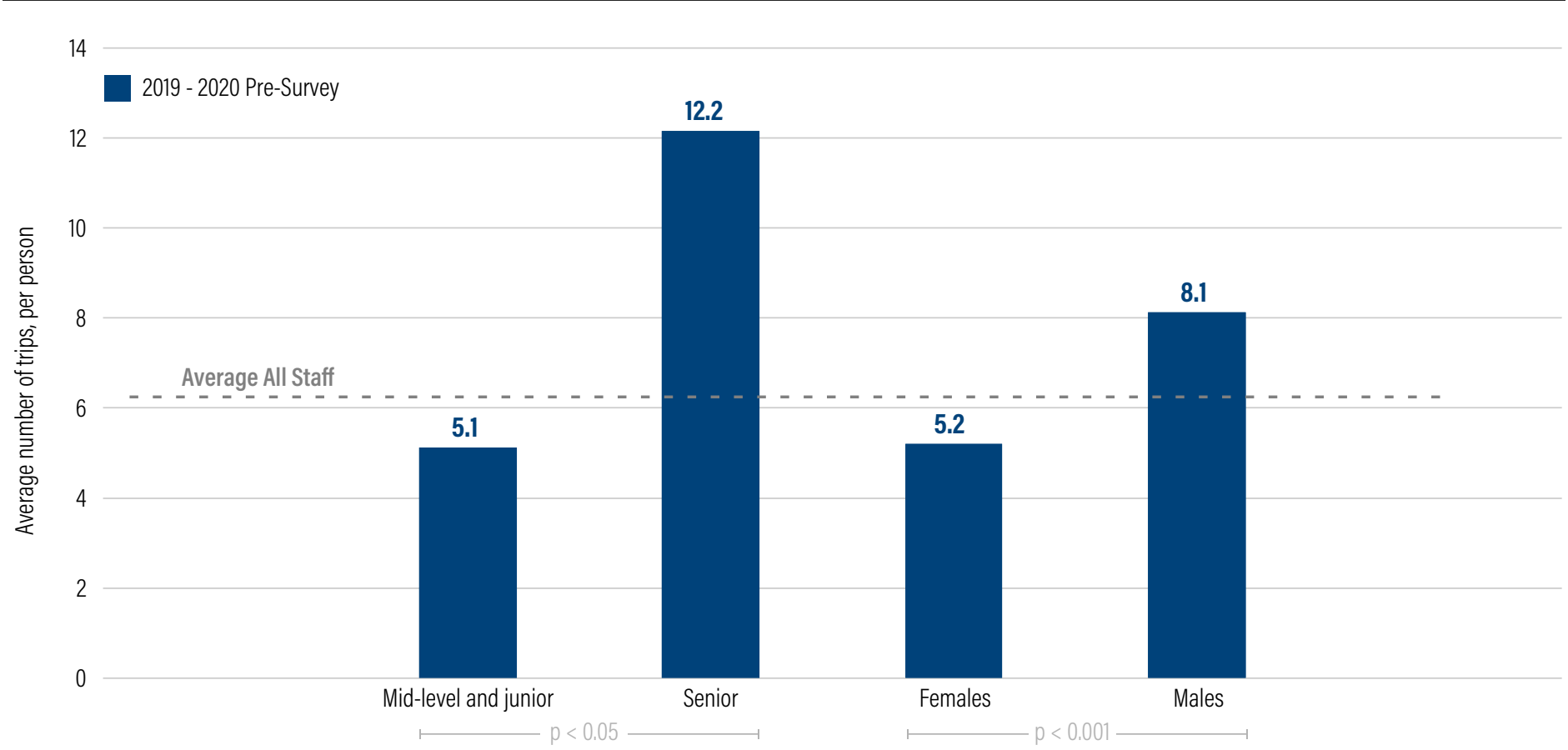

Source: WRI authors.

Also mirroring the administrative data, we find that men traveled significantly more than women. (Average trips per year for men were 8 and for women were 5.) This effect remains even when controlling for country office and seniority level.

\section{What Was the Purpose of Business Travel?}

Travel varied by purpose of trip, with staff reporting that conference participation, relationship building, and project management are top reasons for air travel.

Reasons for travel also vary by seniority (Figure 5). Midlevel staff report traveling more for project management, while junior staff report traveling more for conferences and data collection. In open-ended responses, many people pointed out that travel for conference participation is often important for junior staff's professional development. As one staff member stated, "Speaking at workshops or conferences and relationship building are important ways for junior staff to build their profile in this space and to learn about how to effectively network and collaborate across organizations."
Senior staff travel significantly more for fund raising, relationship building, and speaking engagements.

\subsubsection{Discover: Barriers Pre-COVID-19}

Before COVID-19, what were the staff's perceptions of reducing business travel?

Before COVID-19, a third of respondents reported an intention to reduce their travel in the coming year. Those that traveled the most were very likely to report an intention to travel less in the future: Sixty-five percent of top travelers (those in the top 25 percent of travelers) reported intentions to reduce business travel.

What were the behavioral and institutional barriers in replacing business travel with virtual or non-air travel, and did those barriers influence travel behaviors and intentions?

Perceived barriers can be as important as structural barriers. The survey explored staff's perceptions of air travel reductions on the following key dimensions: 


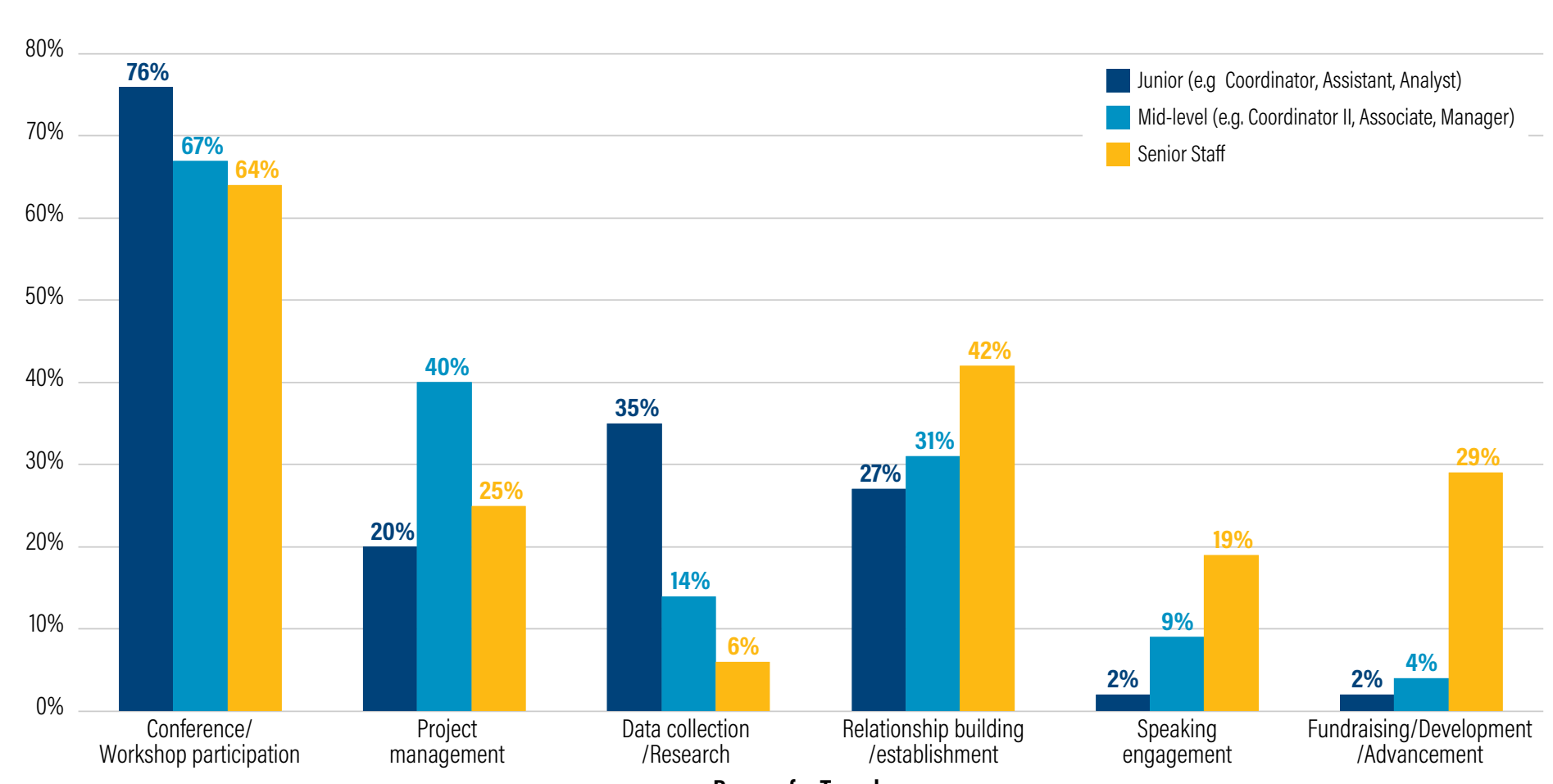

Note: Percentages do not sum to $100 \%$ per color because a single trip may have multiple purposes.

Source: WRI authors.

Perceptions of control over travel reduction decisions: Staff were asked if they agreed or disagreed with the statement: It is mostly up to me whether I reduce air travel for work in the future. Decisions in which we feel low levels of control can be especially difficult to overcome. Asking people to reduce travel when they do not believe that they have control over their travel decisions is likely to be unsuccessful (and probably frustrating). Before COVID19 , more than half of travelers believed that the decision to reduce their air travel was out of their control, indicating a clear role for organizational policies and norm setting.

Possibility: Research from behavioral science offers the insight that people's failure to change their behavior may not reflect real constraints but instead be the result of their perceptions of constraints. Pre-COVID-19, a third of staff reported believing that air travel reduction was somewhat or totally impossible. As discussed later in this paper, the COVID-19 travel ban tested and changed many of these assumptions.

Expectations and Norms: Staff were asked if they agreed or disagreed with the statement: My supervisor(s) would support me reducing my air travel for work in the future and if they agreed or disagreed with the statement: $M y$ peers at my organization would approve of my reducing air travel for work. WRI does not have a policy mandating travel, but some teams certainly have work plans, external partners, and budgets that dictate travel and likely produce expectations and norms around air travel. As a result, 38 percent of staff disagreed with the statement: My supervisor would approve of reducing travel over the next 12 months. Almost a full third (31 percent) of staff disagreed with the statement: My peers would approve of my reduction in travel. See Figure 6 for more detail on staff's perceptions on air travel pre-COVID-19.

Do these perceptions influence travel reduction behaviors and future intentions?

Travel behaviors: There appears to be a relationship between perceptions and travel frequency: Descriptively, we see that people who report that a reduction is impossible and out of their control fly more than other staff on average, although only reporting that a reduction was possible was statistically significant. (See Figure 7).

Note that statistical differences are noted by asterisks in the figure below and in future graphs. 
Figure 6 | Perceptions of Travel Reduction, Pre-Survey (Percentage Agreeing and Disagreeing)

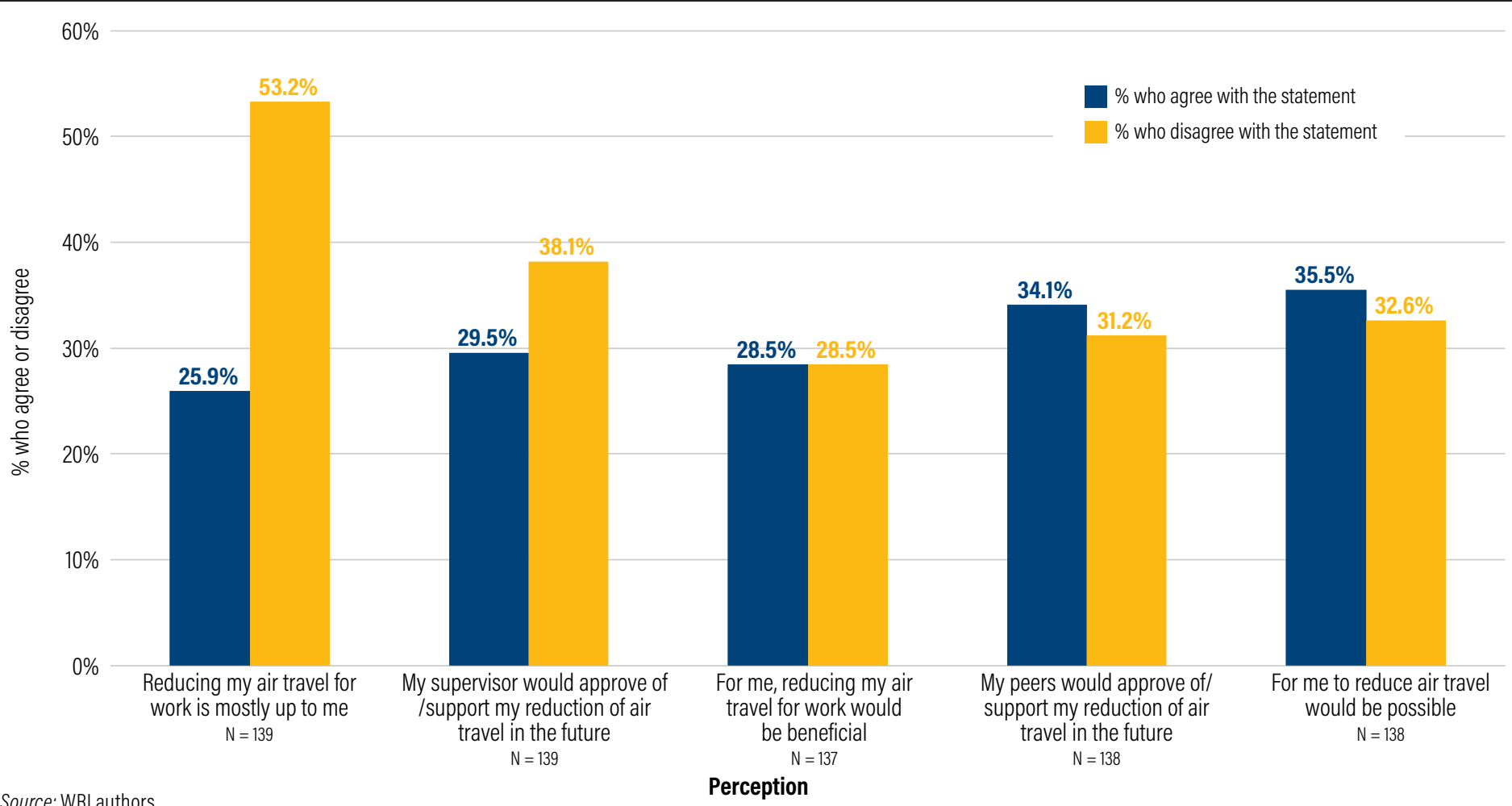

Source: WRI authors.

\section{Perception}

Figure 7 | Trip Frequency by Perception of Travel Reduction, from Pre-Survey (Average Number per Person per Year)

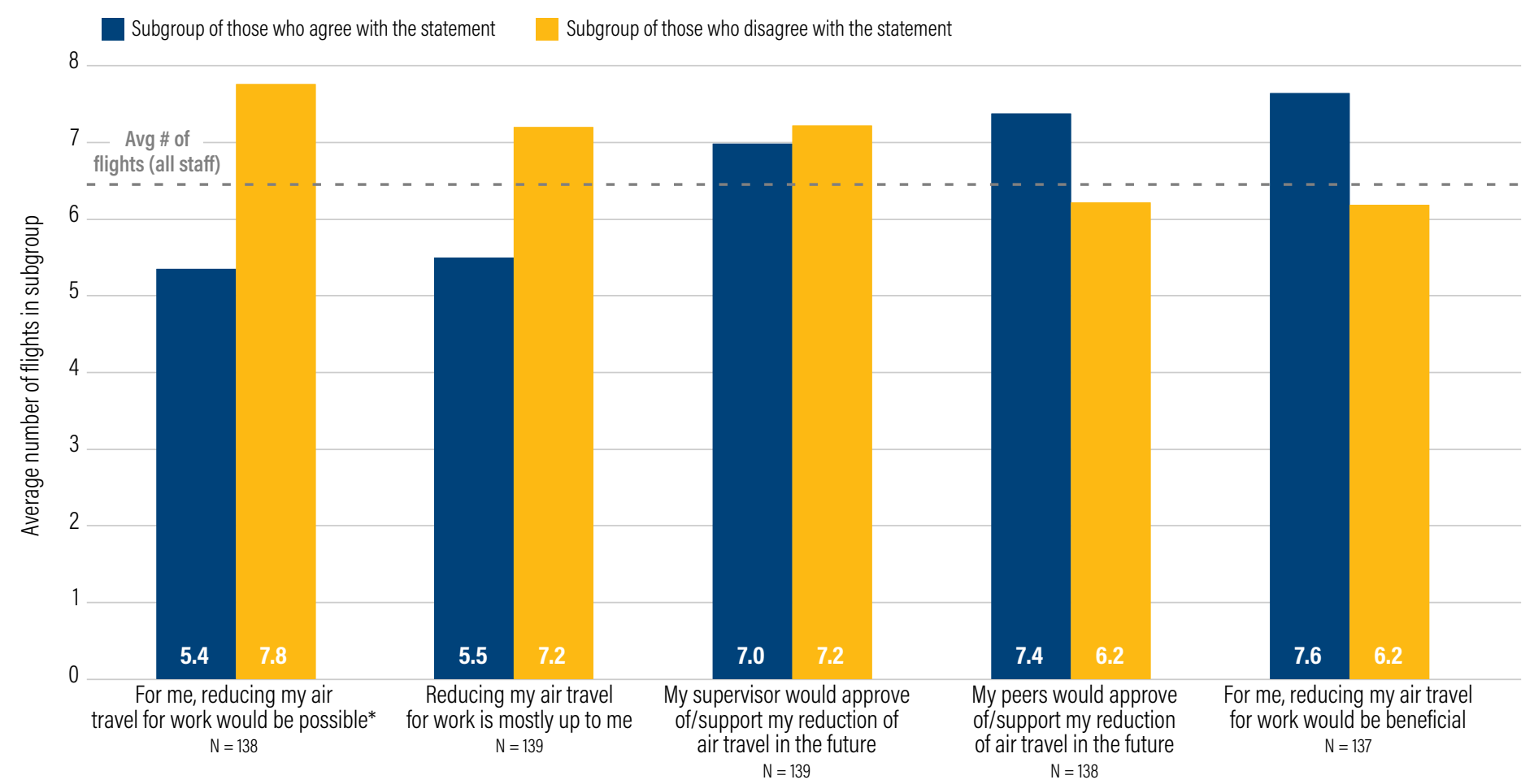



in the 2019 Survey

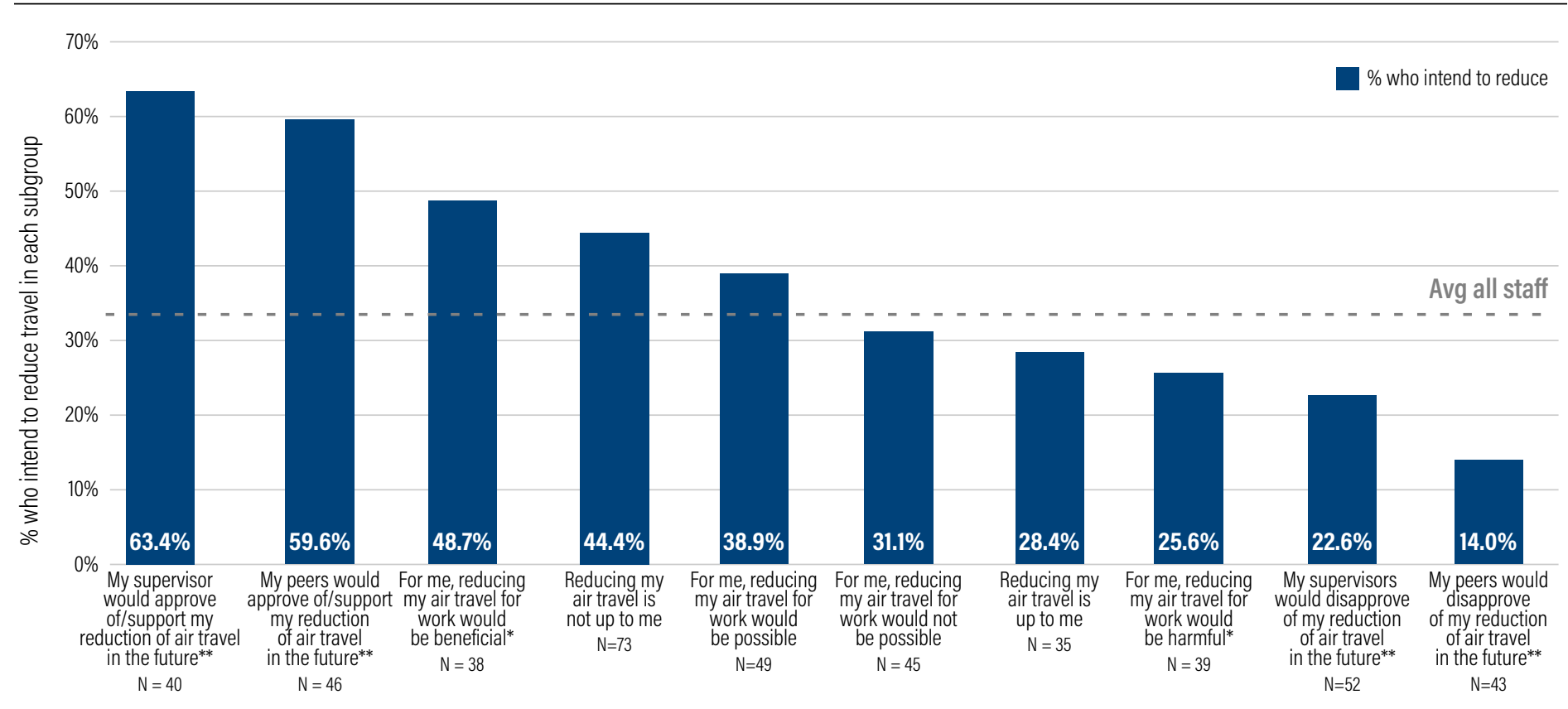

Source: WRI authors.

Perception

Future intentions: In the pre-survey, people were asked if they intended to reduce their business travel over the next 12 months. When we explore people's intentions in light of their perceptions, we see that staff who report that a reduction is possible and approved by supervisors are statistically significantly more likely to report an intention to reduce their travel (Figure 8). That people are more likely to intend to reduce travel when they believe that reduction is possible and organizationally approved (via supervisors) again indicates the clear role for organizational action in supporting individual behaviors.

\section{Pre-COVID-19, What Were the Pain Points, and What Opportunities Existed to Reduce Business Travel?}

It can be easier to change behaviors that have noted pain points and relatively effective and available alternatives. Our survey found that air travel had multiple pain points, as well as air travel substitutes that were perceived as promising and effective. Specifically, staff reported that air travel is uncomfortable and time-consuming. The most cited reason for avoiding air travel, with 66 percent of staff selecting, was the "time investment" (Table 2). As mentioned in Section 1.1, WRI's cumulative time lost to travel is significant: In 2019, WRI staff spent more than 19,700 hours flying.
Table 2 | Top Reasons for Avoiding Business Travel $(\mathrm{N}=139)$

\begin{tabular}{|l|r|}
\hline \multicolumn{2}{|c|}{$\begin{array}{c}\text { "PLEASE SELECT THE TOP REASONS YOU MAY } \\
\text { AVOID BUSINESS TRAVEL. SELECT TWO" }\end{array}$} \\
\hline REASON & $\begin{array}{r}\text { PERCENT } \\
\text { SELECTING }\end{array}$ \\
\hline Time Investment & $66 \%$ \\
\hline High Costs & $46 \%$ \\
\hline Alignment to Work & $35 \%$ \\
\hline Environmental Impacts & $31 \%$ \\
\hline Source: WRl authors. & \\
\hline
\end{tabular}

Even before Zoom became a household word, it was clear from our pre-survey that virtual conferencing was a promising substitute. Virtual conferencing was deemed to be by far the most feasible alternative to business travel, with over 80 percent of respondents ranking it as the most feasible alternative to air travel, with rail a distant second.

Just six months after the pre-survey, the COVID-19 crisis forced staff to reduce travel to zero and provided a unique research opportunity. 


\subsubsection{Discover: Opportunities Post-COVID-19}

\section{How Did COVID-19 Change Staff's Business Travel Behaviors?}

Based on responses to the post-survey, we estimate that WRI staff canceled 2,543 flights from January to June 2020. Almost all (nearly eight out of ten) staff replaced their forgone travel with virtual alternatives. The remaining staff either canceled or indefinitely postponed their engagements. Replacement did not vary within the organization. Senior to junior staff in every global office replaced the majority of their travel with virtual alternatives.

\section{What Was the Staff's Perception of the Effective- ness of Virtual Replacement, and Did This Vary within the Organization?}

Virtual replacement was more effective and feasible than staff previously thought. Specifically, 64 percent of staff agreed with the statement: Reducing business travel was more feasible and can be done more effectively than I thought. The most senior staff were most likely to agree (Figure 9). Eighty-eight percent of the executive team, the most senior members of WRI, agreed with the statement. While they constituted a small portion of the sample, they are important to note because they represent an opportunity to influence the organization's norms, tone, and policies.

\section{Effectiveness of Virtual Replacement by Type of Activity}

While virtual replacement was generally deemed effective, there is some variance by activity. We found that the effectiveness of virtual communications as a replacement is highly dependent (Figure 10). Based on effectiveness margins (the proportion of respondents rating virtual communications as very effective or effective minus the proportion rating them as ineffective or very ineffective), respondents indicated that virtual communications are effective at replacing travel for project management, speaking engagements, and conference or workshop participation and less effective at replacing travel for fund raising or development, data collection or research, and relationship building or establishment.

For all types of travel, we find significant differences by gender. Women found virtual replacements more effective than men did for every activity except fund raising and relationship building or advancement.

Figure 9 | Percentage of WRI Staff Agreeing that Travel Reduction Was "More Feasible and Effective Than I Thought," by Seniority and Gender $(N=408)$

$100 \%$

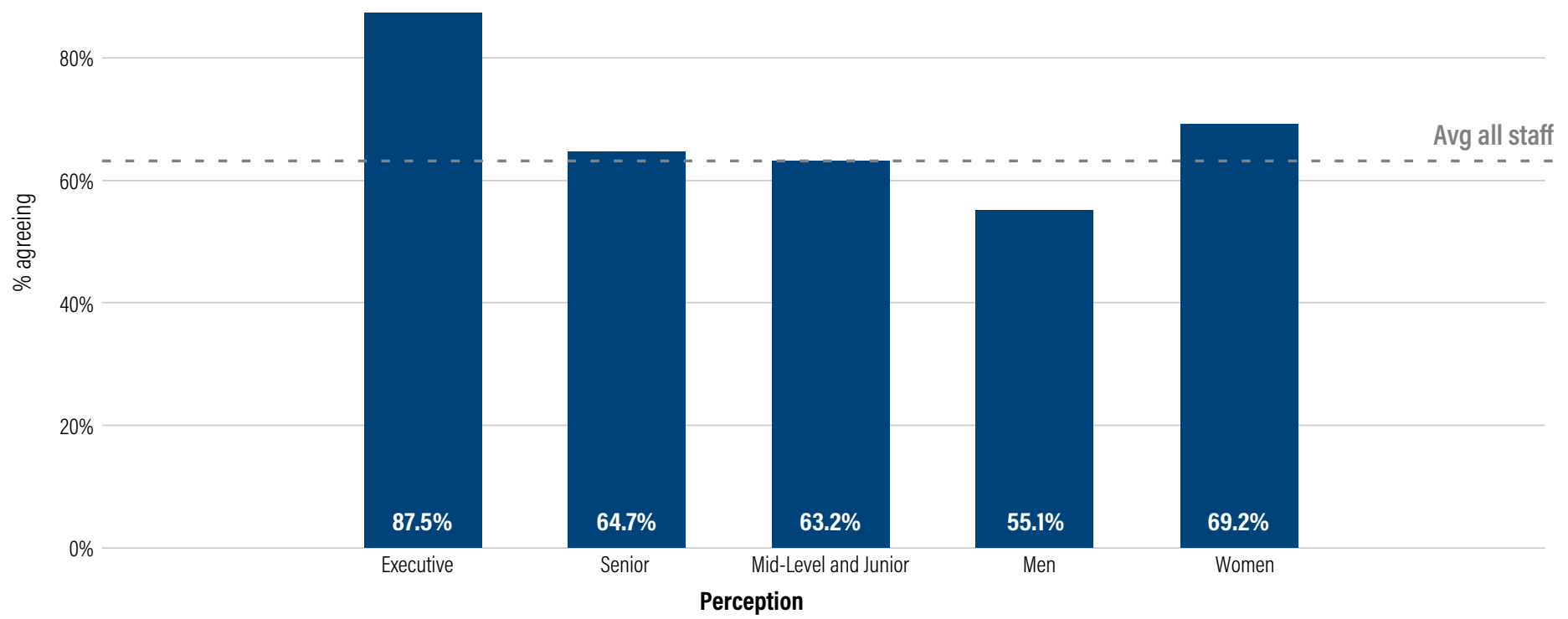




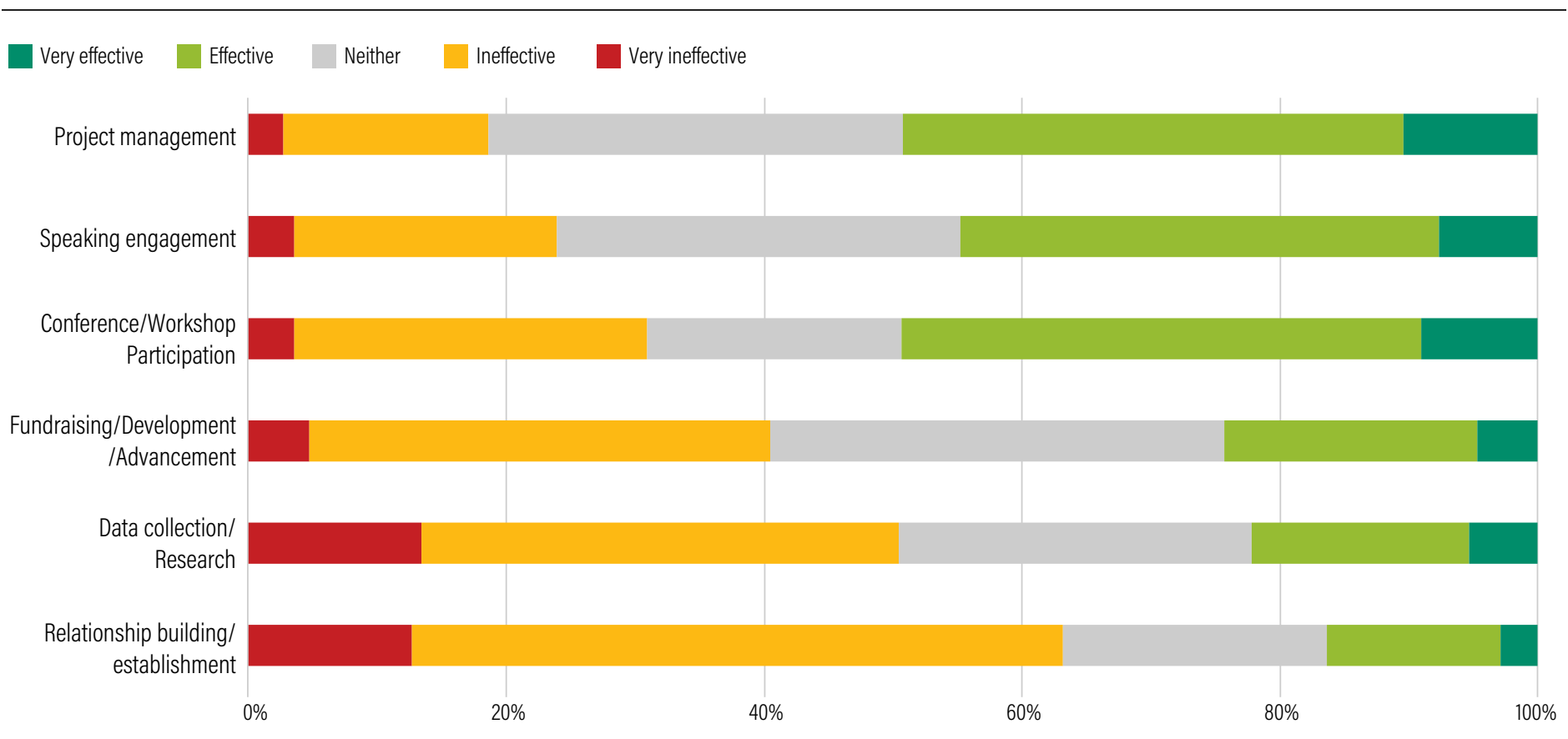

Source: WRI authors.

Employees of color are more likely to support virtual replacements for travel than their white counterparts. In some cases, these differences are significant. When it comes to conferences, 59 percent of employees of color reported that virtual replacements were effective, compared to 39 percent of white employees $(p=.01)$. For relationship building, half (50 percent) of employees of color reported that virtual replacements were ineffective, while a majority (63 percent) of white employees did $(\mathrm{p}=0.1)$.

\section{Did the Post-COVID-19 Experience Influence Perceptions of Reducing Business Travel?}

In behavior change literature, it is unusual to see large and significant changes in people's perspectives, especially in a short amount of time. However, the COVID-19 crisis is a once-in-a-generation event that has upended how we work and travel. As a result, post-COVID-19, staff report dramatic and positive changes in how they perceive business travel (Figure 11). ${ }^{23}$

These changes in perception are discussed in detail below.

Control: We see an increase in staff's perception of control moving from 25 to 39 percent agreeing with the statement: It is mostly up to me whether I reduce business travel. Since COVID-19, staff were not formally given more control over their flight decisions. However, during FGDs, staff reported having formal and informal conversations with their colleagues about the effectiveness of virtual replacement and their intention to reduce travel beyond the COVID travel bans. As one FGD member who traveled at least six times a year stated, "[Since COVID] we experienced that some events can be replaced virtually.... We are now moving in that direction. In the future we will carefully choose which missions we go on and for which kind of events we travel."

Possible: In the pre-survey, only 36 percent of staff agreed that travel reduction was possible; in the post-survey, 63 percent of respondents agreed. This change in perception is consistent across offices, levels, and travel frequencies. During the FGDs, we heard that reduction seemed more possible during COVID because individuals experienced its success. Meetings and conferences that people had assumed had to be in person were held effectively virtually. In addition, everyone in the sector moved to virtual. Staff did not miss out on opportunities to meet in person since every organization was similarly travel-restricted.

Expectations or Norms: The greatest difference we see post-COVID-19 is the perception that supervisors would 
Figure 11 | Changes in Perceptions of Reducing Business Air Travel, from Pre-Survey to Post-Survey

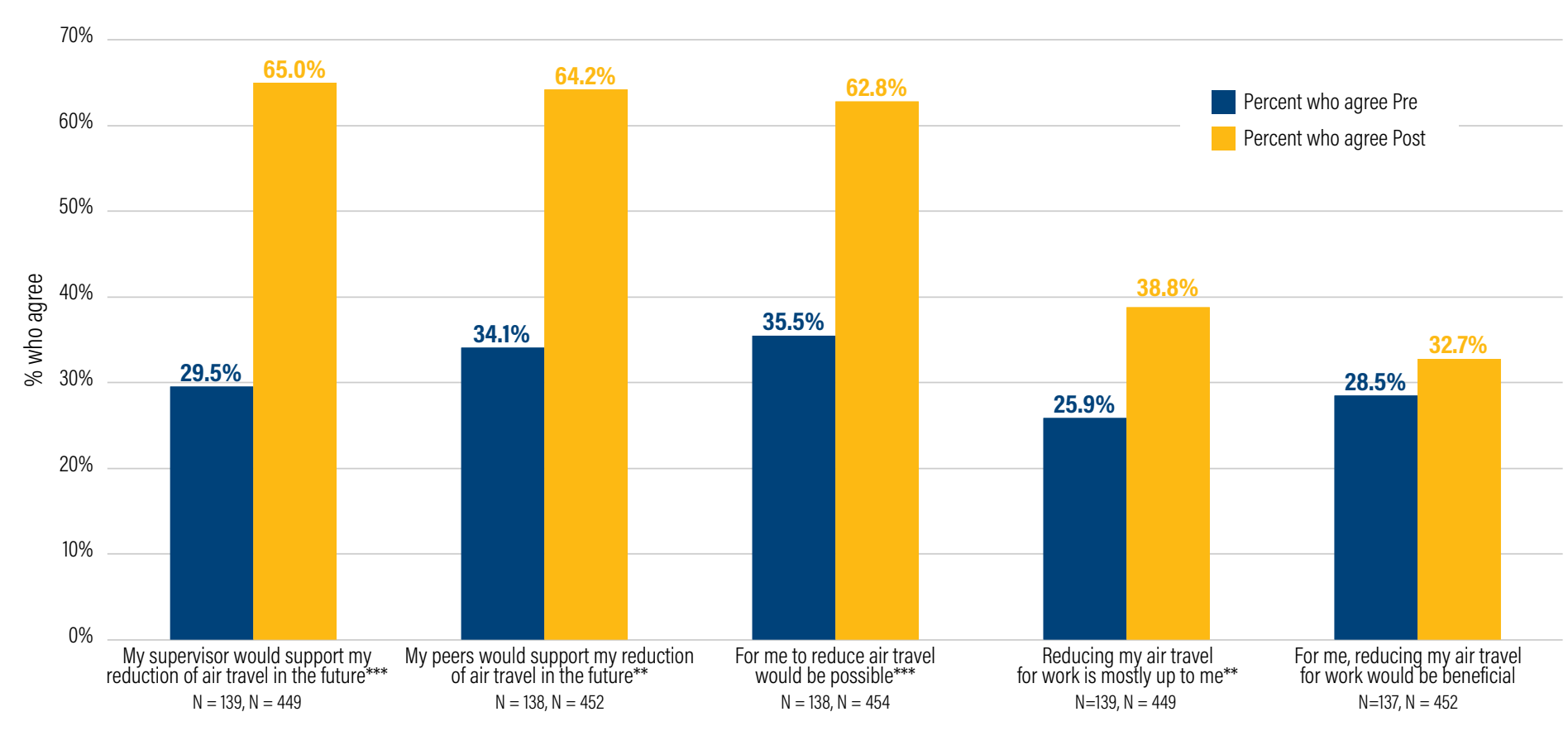

Note: Pre-survey sample sizes are shown first; post-survey sample sizes second.

Perception

Source: WRI authors.

support a reduction in travel, shifting from 29 percent agreeing to 69 percent agreeing with the statement: $M y$ supervisor would support my reducing business travel in the next 12 months. From FGD conversations, it appears that staff are having conversations with their teams, supervisors, and often funders about their positive experiences with travel reduction. As one FGD member noted, "We discussed [effective reduction] as a team and also with our funders.... We are restructuring our meetings, and it has been effective..., so working with our funders, we have also reallocated the travel budget to our communications budget."

Finally, we find a small increase in the percentage of staff reporting that decreased business travel would be beneficial, moving from 29 percent agreeing to this statement in the pre-survey to 33 percent agreeing in the post-survey.

\section{Did the Post-COVID-19 Change in Perceptions Vary within the Organization?}

While perceptions changed across the board, the largest single change was in junior staff's perception that travel reduction would be supported by supervisors, moving from 30 percent agreeing in the pre-survey to 65 percent agreeing in the Post-Survey. This shift has implications for the success of future reduction efforts since junior staff were most likely to report low levels of control over their travel decisions pre-COVID-19.

Senior and executive staff report the largest changes in the perception that reduction is

possible, moving from 27 percent reporting that a reduction in business travel is possible in the presurvey to 68 percent agreeing in the post-survey;

- within their control, moving from 31 percent reporting that a reduction in business travel is within their control in the pre-survey to 56 percent agreeing in the post-survey (an increase of 25 percentage points); and

- beneficial, moving from 35 percent reporting that a reduction in business travel would be beneficial in the pre-survey to 50 percent agreeing in the post-survey.

We also see differences between high- and low-frequency travelers with more frequent travelers, especially the highest frequency travelers (those in the top quartile) reporting lower than average changes in expectations to travel ("my peers or supervisor would support") but above average changes in the perception that reduction is possible (Figure 12). 
Figure 12 | Percentage Point Change in Perceptions of Reducing Business Air Travel, by Travel Frequency, from Pre-Survey to Post-Survey

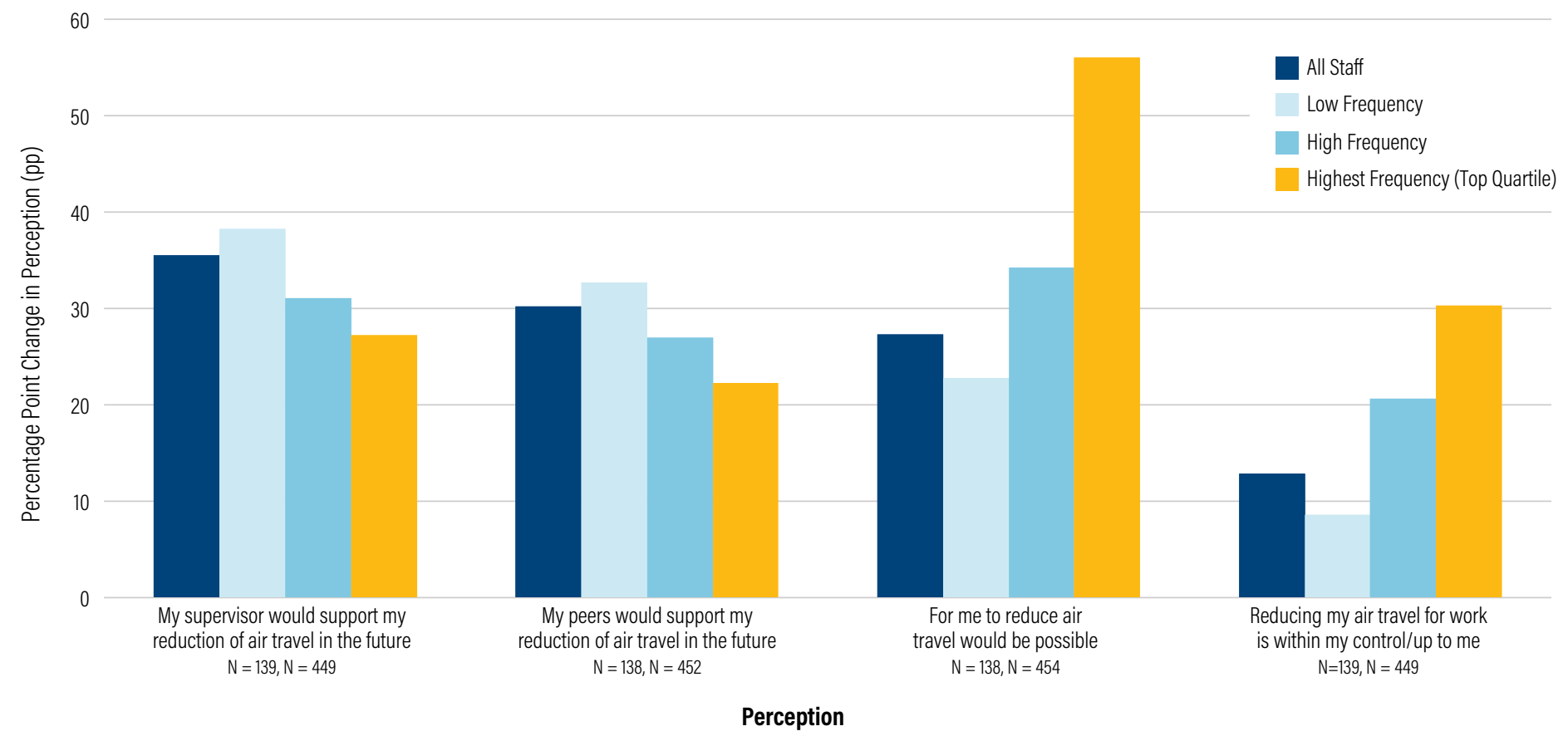

Note: Pre-survey sample sizes are shown first; post-survey sample sizes second.

Source: WRI authors.

We also observe differences in how men and women perceive reducing business travel in the post-survey. While both groups report similar levels of social support to reduce travel from supervisors and peers, women are statistically significantly more likely to report that reductions are possible and beneficial. The current research does not provide sufficient data to unpack the reasons for the consistent gender differences in travel behaviors and perceptions. This is a fertile area for future research.

\section{Did Experience with Reduced Travel Influence Future Intentions and Commitments?}

Intentions: Intentions to reduce travel increase significantly post-COVID-19. We see a dramatic change in the percentage of staff agreeing with the statement, "I intend to reduce travel," moving from 34 percent agreeing in the pre-survey to 61 percent agreeing in the post-survey ("Post-pandemic, I intend to reduce my travel"). We see a positive relationship between seniority level and change in intention to reduce travel (Figure 13).

Intentions to reduce travel are also correlated with positive perspective on control, benefit, and peer approval to reduce travel (Figure 14).
Future Commitments: The post-survey asked if staff would make a commitment to reduce their travel. Seventy percent of all staff agreed to make a commitment. (This commitment is relatively stable across levels, with 65 percent of junior staff, 72 percent of mid-level staff, and 81 percent of senior staff making a commitment.) Exploring the relationship between perceptions and commitments, we find that staff who report that travel reduction is approved of by peers and supervisors, beneficial, possible, and within their control are significantly more likely to make a commitment to reduce travel after COVID-19 restrictions ease (Figure 15). This finding underlines the critical role of organizational policies and norms to support individual efforts to reduce business travel.

Finally, we explore how key perceptions changed by level and gender. Women were significantly more likely than men to believe that reducing business travel is more feasible and effective than they previously thought. Looking at seniority level, we find that senior staff-who on average travel three times as much as mid-level and junior staffreport the highest levels of agreement across all three domains: the perception that travel reduction is more effective than previously thought, an intention to reduce, and a commitment to reduce (Figure 16). 
Figure 13 | Percentage Changes in Intention to Reduce Travel, by Seniority, from Pre-Survey to Post-Survey

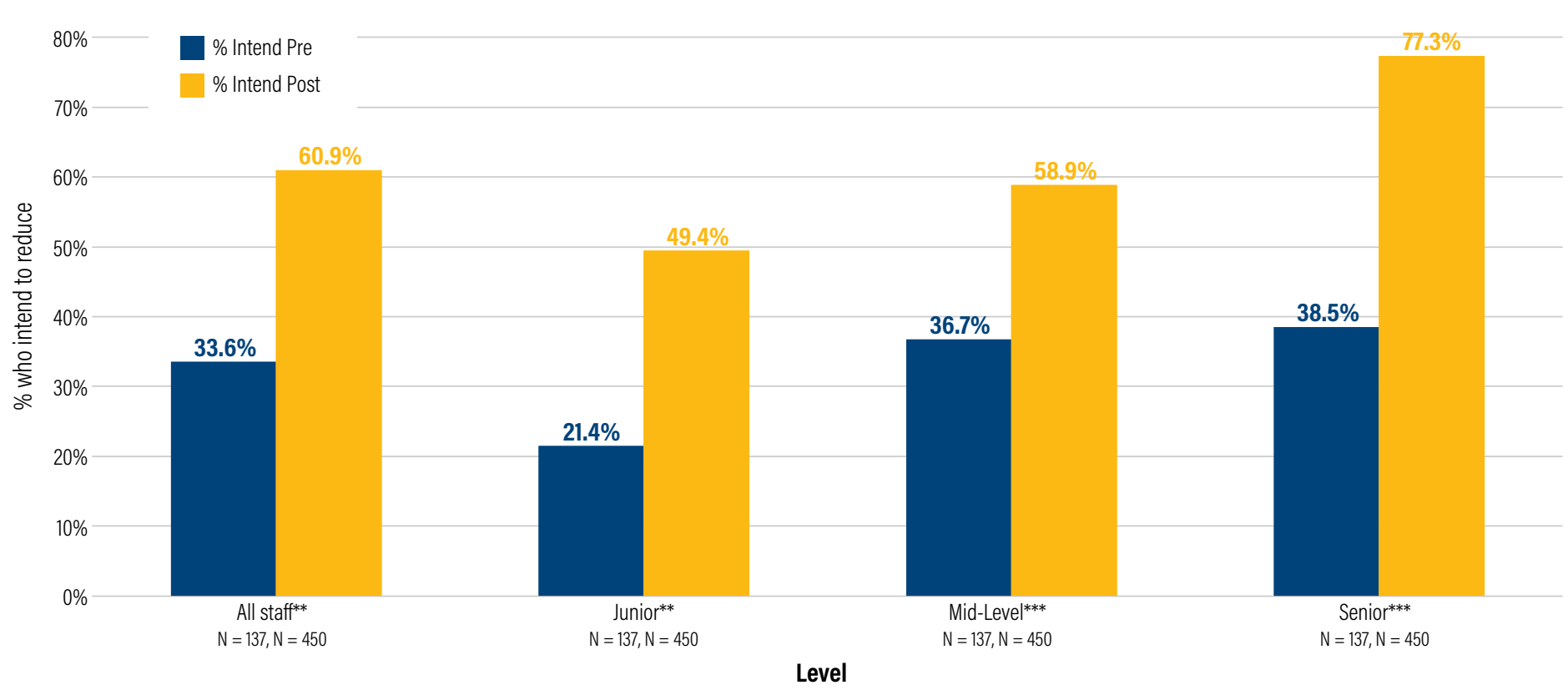

Note: Pre-survey sample sizes are shown first; post-survey sample sizes second.

Source: WRI authors.

Figure 14 | Percentage of WRI Staff Reporting an Intention to Reduce Travel by Perception of Travel Reduction, from Post-Survey

$100 \%$

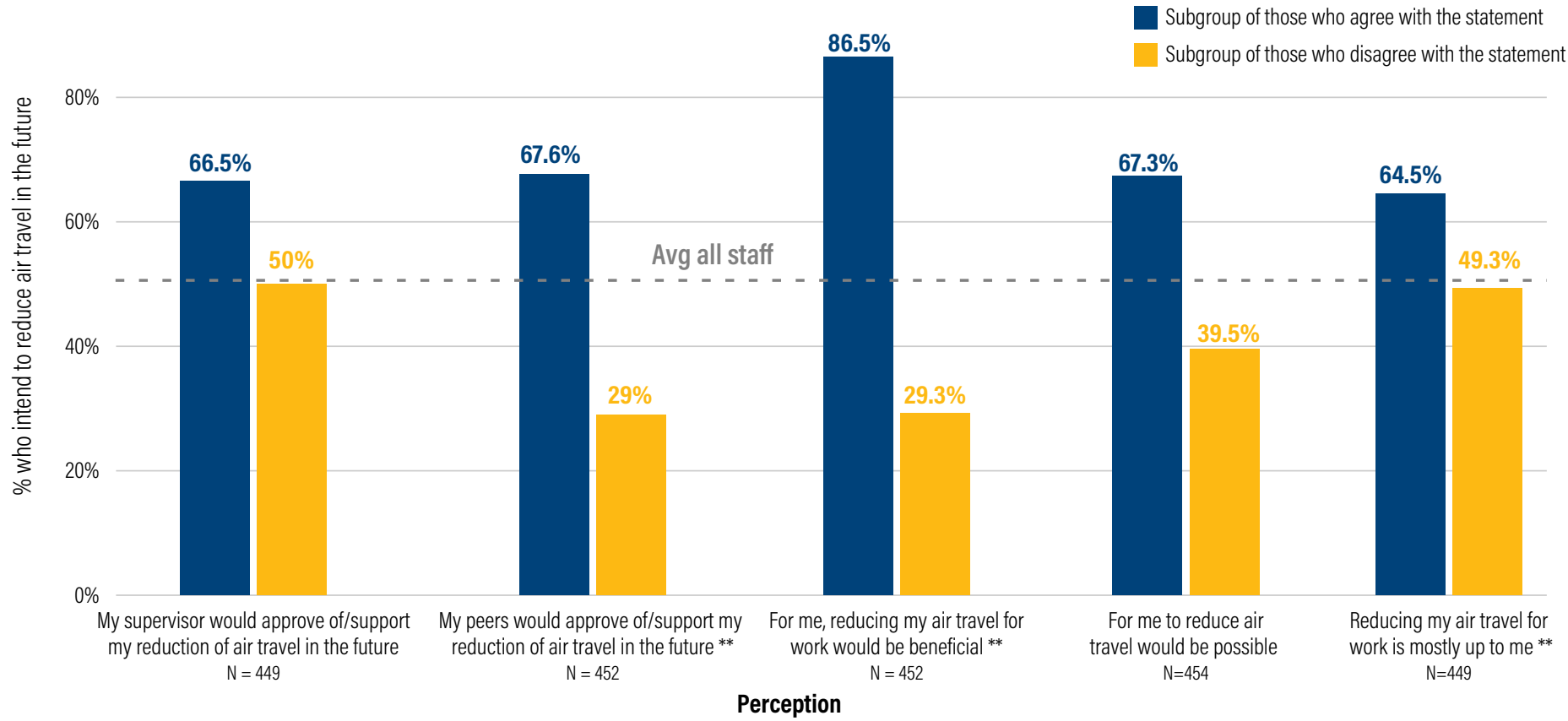

Source: WRI authors. 
Figure 15 | Percentage of WRI Staff Setting a Commitment to Reduce Travel by Perception of Travel Reduction, from Post-Survey

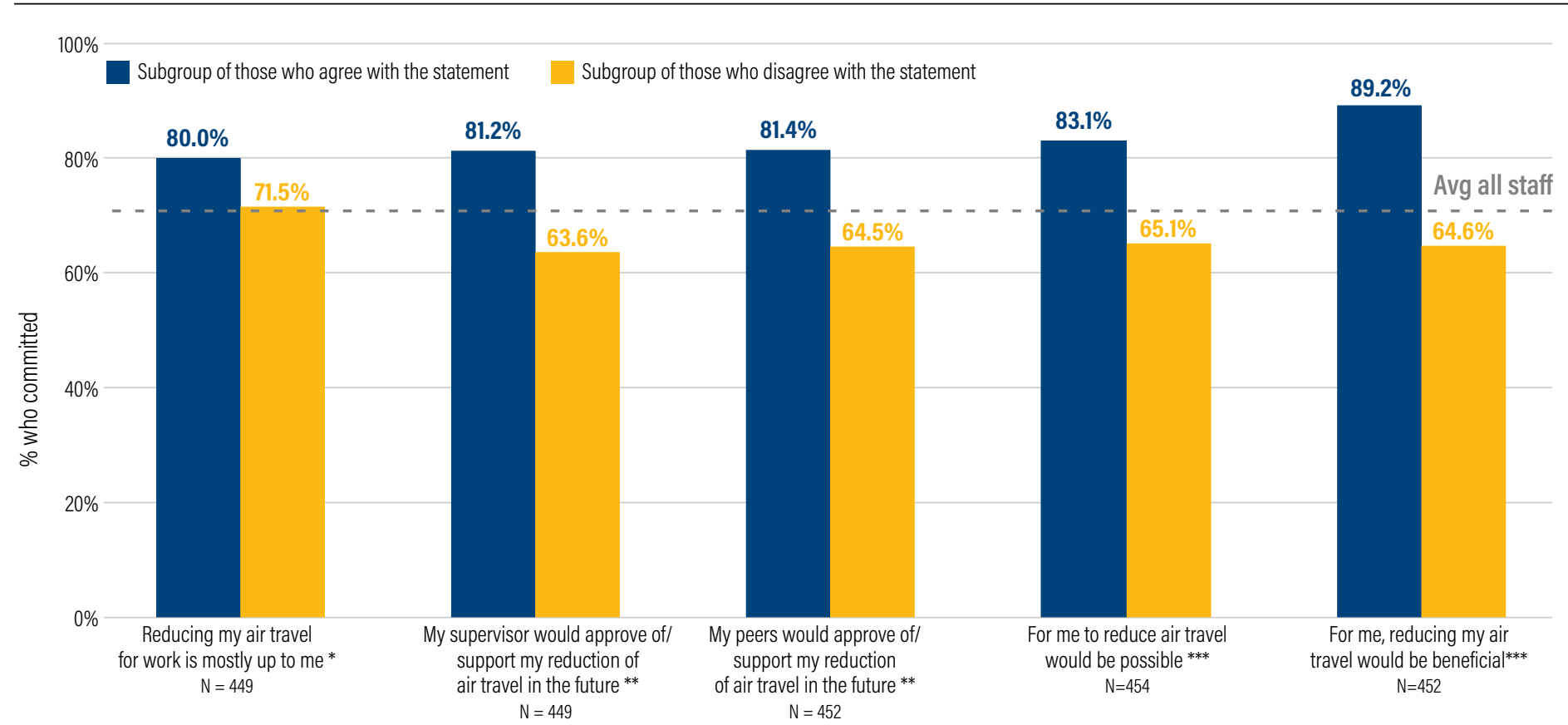

Perception

Source: WRI authors.

Figure 16 | Perceptions, Intentions, and Commitments of Travel Reduction, by Seniority (Percentage Who Agree with Each Statement)

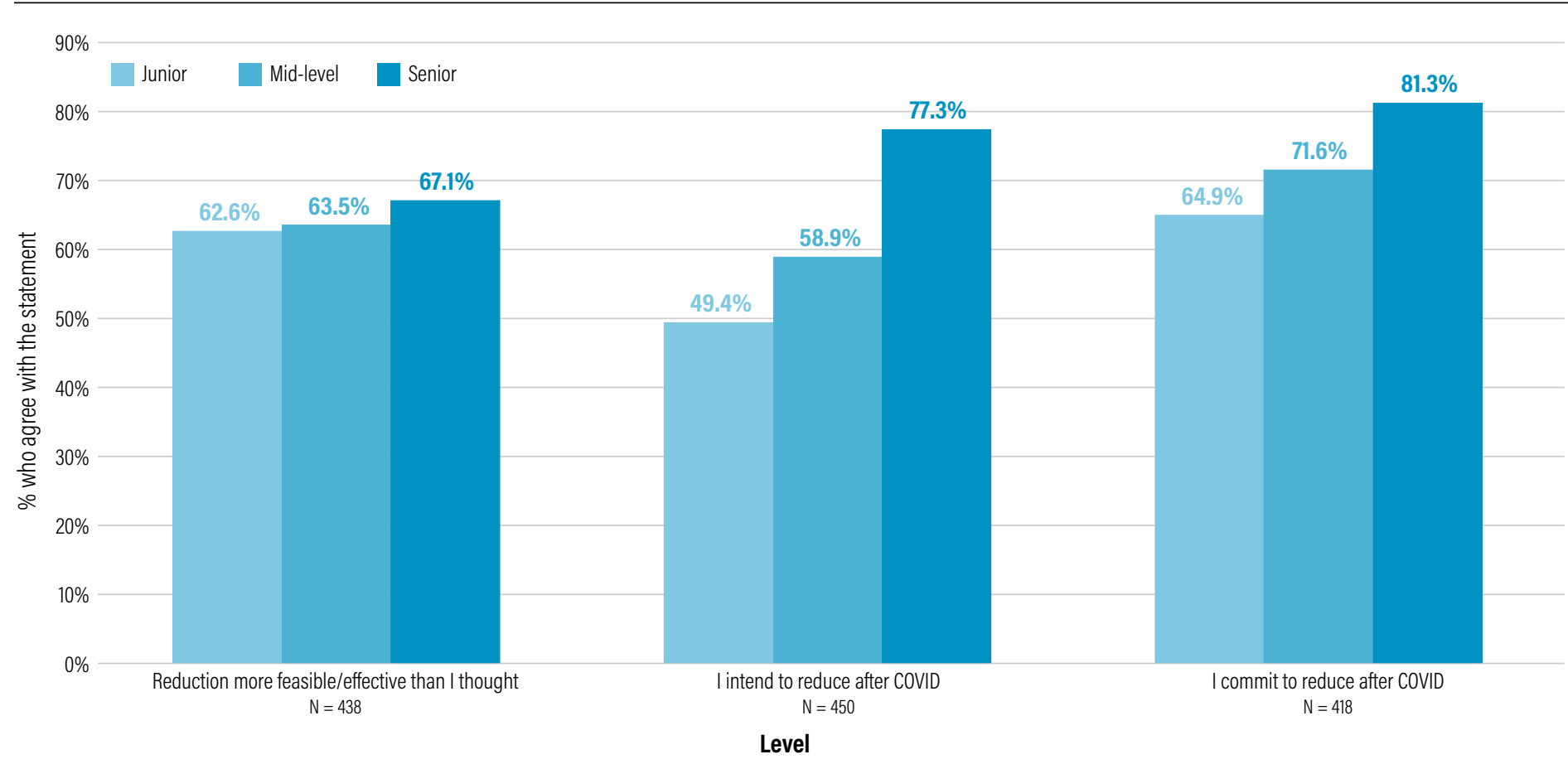

Source: WRI authors. 


\subsubsection{Design: Implications for Organizations and Employers}

\section{WHAT ARE THE BARRIERS AND OPPORTUNITIES PRESENTED BY SUSTAINED REDUCTIONS AND DO THESE VARY WITHIN THE ORGANI- ZATION?}

Critically, we find that respondents expect that reduced business travel post-COVID-19 will have positive effects on job satisfaction, work quality, life-work balance, and motivation. As shown in Table 3, the largest net positive margins were reported for life-work balance (61 percent), quantity of work (27 percent), and overall job satisfaction (19 percent). The only negative margin we find is a significant concern that reduced travel will negatively affect collaboration with colleagues and/or external partners (-35 percent).

\section{COLLABORATION}

As one staff member commented in an open-ended survey response, "I place a lot of value on developing good relationships with external partners, and interacting in person contributes a lot to that. So losing that could have a negative impact on (my) motivation/job satisfaction."
Many people specifically mentioned the importance of in-person collaboration and connection to fund-raising activities. As one respondent wrote, "Some of the most effective fund raising is done through informal in-person meetings, which is quite difficult to do online. I am concerned that fund raising will be more challenging if we aren't able to be present and visible at key events."

While collaboration was a significant concern for many, staff reporting a concern that reduced travel would negatively affect collaboration were about as likely as staff on average to report an intention to reduce travel (6o percent of all staff versus 58 percent of staff citing a negative impact on collaboration) and about as likely as staff on average to report a commitment to reduce travel ( 71 percent of all staff and 74 percent of staff citing a negative impact on collaboration).

Nearly a quarter of respondents (from junior to senior staff) were concerned that requiring junior staff, who travel much less than average, to reduce their travel would decrease motivation and preclude them from valuable professional development opportunities. As one junior

Table 3 | Effects of Reduced Business Travel Post-Pandemic on Various Aspects of Work (Percentage)

\begin{tabular}{|c|c|c|c|c|}
\hline $\begin{array}{l}\text { POST-PANDEMIC HOW WILL REDUCED AIR TRAVEL } \\
\text { IMPACT THE FOLLOWING? }\end{array}$ & $\begin{array}{r}\text { (1) } \\
\text { VERY NEGATIVE OR } \\
\text { NEGATIVE }\end{array}$ & $\begin{array}{r}\text { (2) } \\
\text { NEITHER }\end{array}$ & $\begin{array}{r}\text { (3) } \\
\text { POSITIVE OR VERY } \\
\text { POSITIVE }\end{array}$ & $\begin{array}{r}\text { (3)-(1) } \\
\text { NET MARGIN: } \\
\text { \%POSITIVE RATINGS - } \\
\text { \%NEGATIVE RATINGS }\end{array}$ \\
\hline Life-work balance & $2 \%$ & $28 \%$ & $63 \%$ & $61 \%$ \\
\hline Quantity of work & $11 \%$ & $42 \%$ & $38 \%$ & $27 \%$ \\
\hline Overall job satisfaction & $16 \%$ & $41 \%$ & $35 \%$ & $19 \%$ \\
\hline Motivation & $21 \%$ & $41 \%$ & $29 \%$ & $8 \%$ \\
\hline Quality of work & $25 \%$ & $35 \%$ & $31 \%$ & $6 \%$ \\
\hline Collaboration with colleagues/external partners & $52 \%$ & $23 \%$ & $18 \%$ & $-35 \%$ \\
\hline
\end{tabular}

Source: WRI authors. 
staff member shared, "I have never gone on a business trip and would really like to have that chance; it would help me have direct contact with the content of my work and develop stronger bonds with partners."

\section{What Behaviorally Informed Policies and Programs Would Support Staff in Maintaining Reduced Business Travel?}

Set new organizational practices and create explicit norms: Staff who felt organizationally supported (by peers and supervisors) and empowered to reduce air travel were significantly more likely to make a commitment to reduce travel. This finding highlights the role of organizational practices and norms. Specifically, many survey and FGD respondents noted the importance of leadership and senior staff to set an example and create new norms regarding travel reduction. Eighty-one percent of senior staff reported a commitment to travel less post-COVID and therefore have the opportunity to effectively model new norms by publicly sharing their travel reduction commitments.

To operationalize the practice of creating new norms, many staff suggested that leadership announce an organizational air travel-reduction goal. In addition, many suggested that senior staff share their personal travelreduction commitments in public and accountable ways. Organizations could invite senior staff to share their reduction commitments and ask their teams to do the same. ${ }^{24}$ One way to hold leaders accountable would be to ask them to report on their progress toward their goal in quarterly updates.

In terms of practices, team leaders should be encouraged to meet with staff to explicitly discuss what travel was effectively replaced with virtual and what travel staff view as necessary. Comments during FGDs indicate that some supervisors are informally engaging in these discussions. However, organization-wide policy would ensure that these conversations are happening consistently.

In addition, organizations could create guidelines, like a hierarchy of travel priorities and helpful steps to determine when travel is essential and for whom. Staff requesting travel would have to confirm that the travel requested
Figure 17 | ||lustrative Air Travel Guidance

\section{WRI's Air Travel Guidance and Checklist}

WRI TRAVEL PRIORITIES:

1. Relationship building (for new relationships)

2. Data collection

3. Annual project management

4. Annual collective event (like COP)

5. Professional development, especially for younger staff/staff with no/very low prior travel

AIR TRAVEL EMISSIONS JUSTIFICATION CHECKLIST:

$\square$ This trip advances at least one travel priority (above)

$\square \quad$ There is no virtual option for this trip

$\square$ There is no rail or car option for this trip

$\square$ There is no regional colleague who can make a shorter trip

Source: WRI authors.

meets the criteria in the guidance. See Figure 17 for an illustrative example and Appendix $\mathrm{G}$ for an enhanced travel request form sample.

Design behavioral interventions to motivate travel reductions: Recent behavioral research provides evidence that giving people direct feedback on how their behavior compares to their peers can decrease energy consumption. (Allcott and Rogers 2012) In addition, there is evidence that making pledges can be effective in changing behaviors, especially around resource conservation. (Katzev and Wang 1994). Taken together, these insights create the pieces of a promising behavioral intervention to decrease air travel. In January 2020, WRI launched a pilot project inspired by these behavioral insights. The project sent behaviorally designed emails to WRI staff with snapshots of how their monthly air travel, GHG emissions, and time spent traveling compared to their peers. Emails also prompted staff to make an air travel-reduction pledge.

While the global pandemic halted travel and the full rollout of the pilot project, the intervention's design can be illustrative for future WRI efforts as well as other organizations. See Appendix $\mathrm{H}$ for details on the email pilot project. 
Consider strategic reductions: Organizations might explicitly set up a progressive travel reduction effort by encouraging ambitious but strategic reductions for frequent travelers whose travel can be substituted (either with fewer trips or with virtual replacements) and smaller reductions for staff who travel infrequently, like junior staff and staff from less resourced programs or other groups who have not had the opportunity to benefit from the networking opportunities that can come with travel.

WRI has taken a carbon pricing approach to help fund strategic travel reductions, taxing $\$ 50$ per $\mathrm{MT} \mathrm{CO}_{2}$ e for all business air travel. The revenue from the carbon price goes to a fund for sustainability initiatives and projects to further drive down carbon emissions in the organization (Kamins et al. 2016). Organizations that may not be able to set up internal carbon pricing mechanisms may still consider using estimates of avoided air travel expenses to fund air travel-reduction interventions and virtual technology.

Make virtual and other substitutes easy: Survey respondents pointed to specific suggestions to make virtual substitutes easier, like investing in additional virtual communications tools, noise canceling headphones for staff, and office space specifically designed for virtual meetings with soundproofing, multiple screens, and cameras. Many staff also suggested hiring technical staff to support large webinars and hiring consultants with expertise in designing successful virtual meetings (see Appendix F).

Weave consistent and small changes throughout policies and procedures: Travel policies can link to reference guides that reinforce rail and virtual alternatives. Budgets and financial templates can include lines for virtual communication costs, such as added subscriptions or equipment to reinforce internet capacity, reminding people of travel alternatives and providing additional funds. Further, travel approval processes could provide a definition of essential travel functions, such as early project relationship building, and ask those requesting travel to confirm that the travel requested meets the criteria. These processes could also limit the number of staff traveling to attend the same event.

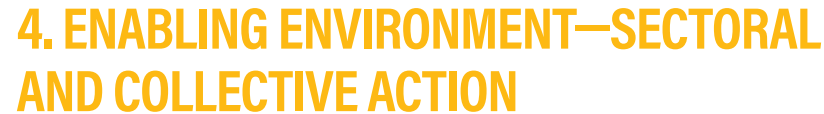

COVID-19 travel restrictions were easing at the time of this publication in many countries and regions. The urgent question now is how the environmental sector, including nongovernmental organizations (NGOs), intergovernmental organizations, funders, academic institutions, and government agencies, can act in concert to design policies and practices that support reductions beyond the pandemic. If organizations act alone, each will be forced to make travel-reduction choices that assume missed opportunities, opportunities that other colleagues and partners are taking advantage of. However, if the sector works in concert to transition to virtual events as often as possible, each actor can make an optimal travel choice for the staff's well-being, operational budgets, and the environment.

In qualitative responses, many staff noted that the pandemic presents a fresh start for the sustainable development sector to collectively change travel behaviors. Reduction efforts will be more successful if virtual collaboration continues throughout the ecosystem, as one staff member alludes to: "For this to work, I think there has to be a collective commitment by the climate community. It is fine to reduce travel during the pandemic because everyone is doing the same, so you're not missing out. But it doesn't work to reduce travel (very much) when the activities are still taking place but you're excluded from them."

\subsection{Reimagine Global Conferences}

Several FGD participants noted the irreplaceability of major events like the UNFCCC's Conference of Parties (COP), a global conference that includes governments, NGOs, businesses, and other leaders. Currently, individual organizations cannot reduce travel to these events without missing opportunities to influence critical decisions. While high-level conferences like the COP may be essential, there is an opportunity for the sector to collectively reimagine how the conference is organized. Could the COP be scheduled in person every other year or be held as smaller, more regional conferences every other year? If an annual meeting is unavoidable, could conference organizers agree to produce travel-reduction guidelines-for example, suggesting limited attendance and adding virtual alterna- 
tives? Rethinking the travel demands of this central event would ease the travel-tension system and likely reduce travel for the entire sector.

\section{Organizations can find opportunities to influence} the larger tension system: Organizations like WRI can influence the sector through their own proposal development, project design, requests for proposals (RFPs), and procurement processes. Research proposals might underline to funders that time and money that would have been spent on air travel can be redirected to producing higherquality research. As a grantee, organizations like WRI can explain to donors how investing more in webinars expands the audience and reach of WRI's work. FGD participants pointed out that holding events virtually diversified their audience and helped them secure speakers that otherwise they would not have been able to host. Others reported webinar audiences that were two to three times larger than for equivalent in-person events. Procurement officers in the sector can also clearly articulate reduced travel priorities to their vendors. For example, RFPs could give priority to vendors and partners that report business travel emissions and have reduction commitments. These messages could communicate an expectation and remind others in the system to consider virtual alternatives. There was no information on the survey that indicated what the effect of this line of action would be, but we believe that experimentally testing this would help inform the wider community.

\subsection{Future Exploration and Research}

\section{Consider a just transition to business travel}

reductions: As we reimagine sustainable business travel, we must also consider that, while decreasing air travel has positive climate impacts, travel reductions exacerbate job loss and income fragility for those who work in the aviation and travel-related sectors. The U.S. Travel Association estimates that domestic and international business travel supported $\$ 700$ billion in economic output and 5 million jobs in 2019 (Cameron and Morath 2021). Economic losses from travel reductions will fall disproportionately on low-wage workers, women in particular, who rely on tourism as their main source of national income (UNWTO 2020). Organizations and the environmental sector must consider just transitions to travel reductions. A just transition refers to approaching behavior change holistically so that transitioning from high to low levels of air travel, for example, is done in ways that support both people and the planet. For specific examples of ways governments and sectors have worked to create just transitions, see Bouye et al. (2019).

Test the next generation of virtual tools: New platforms for collaboration have the potential to address the pain points of reducing business travel that survey and FGD respondents have cited, like difficulty in establishing new relationships and networking during conferences. Many new tools aim to capture the benefits of in-person meetings by recreating offices and event spaces virtually. Platforms like Gather, SpatialChat, and Teamflow allow users to move their avatars through rooms to join conversations, drop in on colleagues, or attend a talk. Some platforms have features that emulate social interactions, like being able to hear conversations fade in or out when an avatar moves closer to or farther from a group. Innovations in collaboration software may help workers establish and maintain more authentic social connections than the current generation of video-conferencing tools.

\subsection{Limitations}

The findings detailed here are relevant to a single organization whose staff are likely to hold views on business travel that differ from organizations that do not focus on the environment. Hence, the results captured may not reflect organizations in different sectors. However, the study sheds light on numerous barriers to reducing business travel, unearthing key reasons for why it is such a difficult behavior to curb beyond a certain threshold, even in an organization whose mission is sustainability.

Some of the findings are based on analyses of changes between the pre- and post-survey results. However, the surveys were sent to different samples: Staff who had used WRI's central travel booking system for the pre-survey and all staff for the post-survey. This difference complicates efforts to draw inferences between the two surveys. However, we proceeded with the analysis because the sample profiles for both surveys were very similar across seniority levels and location with a slight over-representation of mid-level and U.S. staff (see Appendices C and D) and because the self-reported trip frequencies were nearly identical (see Appendix E). 
Furthermore, while the post-survey sample $(\mathrm{N}=457)$ is significant, sample size decreases when exploring subgroups. A larger sample would allow for more nuanced explorations of how key subgroups like parents, people of color, and people with disabilities experience business travel. WRI is part of the Sustainability Managers Roundtable (SMRT) network, which is currently collecting similar survey data from a larger pool of respondents and planning on publishing working papers on the findings. This larger sample size represents a promising opportunity to explore these questions by subgroup.

\section{CONCLUSION}

Human behavior is not fixed. In the wake of COVID-19, WRI staff and travelers around the globe dramatically transformed the way they lived, worked, and traveled. Within the WRI sample, we find massive shifts in flight behaviors with flights decreasing by 92 percent as a result of travel restrictions. The external restrictions led to extraordinary internal shifts in people's perceptions of business-travel reduction: After experiencing the travel ban, people report that reducing business travel is more feasible, effective, and beneficial than they previously thought. And these changes in perception correlate with significant changes in people's increased intentions and commitments to maintain travel reductions beyond the pandemic.

In order to meet Paris Agreement targets of limiting global warming to $1.5^{\circ} \mathrm{C}$, decarbonization strategies in the hard-to-abate aviation sector must include travel demand management. WRI's experience with air travel during COVID-19 illuminates the possibilities. Applying the insights from this working paper will help one NGO make small but significant adaptations and hopefully inspire other organizations to work together to reimagine more sustainable business travel. This is the moment for individual organizations and the environmental sector at large to collaborate around effective travel reduction policies and practices. Transformative global, sector-wide action is possible as we move into the post-pandemic recovery phase. 


\section{APPENDIX A. SUSTAINABILITY: BUSINESS TRAVEL SURVEY (PRE-SURVEY)}

\section{Section 1: WRI Profile}

1) Contact Information

- Email Address:

- Primary WRI Office (choose drop-down): WRI Africa, WRI Brasil, WRI China, WRI Europe, WRI India, WRI Indonesia, WRI Mexico, WRI US

- Program/Center/-Department (choose drop-down): Cities, Climate, Energy, Food, Forest, Oceans, Water, Business, Economics, Finance, Governance, Communications, Operations/HR, Science and Research, Other (platform, project, etc.)

- Level (choose drop-down): Intern, Coordinator (Program or Administrative), Analyst, Associate, Manager, Director/Management Team, Executive Team, 0ther (Secondee, Temporary, etc.)

\section{Section 2: Travel Decisions}

2) How many weeks prior to a trip do you typically book your business travel flights?

SHORT TRIPS (0-3 HOUR FLIGHT)

MEDIUM (3-6 HOUR FLIGHT)

LONG (6+ HOUR FLIGHT)

\section{Business Travel}

3) When do you typically review your (or your team's) business travel data and trends? Select all that apply.
$\square$ Before travel/while planning travel
$\square$ After travel/while managing travel expenses
$\square$ Annually
$\square$ Quarterly
$\square$ Never
$\square$ Other-write in:

4) What type of data do you review when you look at your or your team's business travel trends? Select all that apply.

$\square$ Number of trips/destinations

$\square$ Costs

$\square$ Time

$\square \quad$ Carbon emissions

$\square$ Other-write in:

5) Are you required to justify business travel decisions, for example, connecting travel to strategic plans, work plans, or outcomes?
$\square$ Yes
$\square \quad$ No
$\square$ Maybe/don't know

6) Please select the top purposes for your business travel. Select up to 2.

$\square$ Conference participation

$\square \quad$ Fund raising/development meeting

$\square$ Relationship building/establishment

$\square$ Project management

$\square$ Speaking engagement

$\square$ Data collection/research

$\square$ Other-write in (required): * 
7) Please tell us which phase of a project life cycle you travel the most for.

$\square$ Start-up

$\square$ Planning

$\square$ Implementation

$\square$ Monitoring/improvements

$\square$ Closeout

$\square$ Other-write in:

8) Please select the top reasons you may avoid business travel. Select 2.

$\square \quad$ Time investment

$\square$ High costs

$\square$ Alignment to work

$\square$ Environmental impacts

$\square$ Other-write in (required): *

9) Tell us what you enjoy about business travel and flights. (open answer)

10) Tell us what you dread about business travel and flights. (open answer)

\section{Section 3: Past Behaviors}

11) How frequently did you travel in the last 12 months?

Please enter an estimated number of trips. A trip should count the destinations and not the connecting flights. For example, a round trip between London and DC and any layovers should still count as 1. For multi-city trips, count the destination cities. A one-way flight from DC to a conference in London, followed by a flight to Amsterdam for a meeting before returning to DC would count as two trips.

SHORT TRIPS (0-3 HOUR FLIGHT)

MEDIUM (3-6 HOUR FLIGHT)

LONG (6+ HOUR FLIGHT)

Personal Travel

Business Travel

12) Please rate your level of agreement on a scale of 1 to 7 :

In the past 12 months, I have reduced the number of flights I take for business travel.

$\begin{array}{llllllllll}\text { Strongly disagree } & 1 & 2 & 3 & 4 & 5 & 6 & 7 & \text { Strongly agree }\end{array}$

13) Did you have recurring or regular flights within the last 12 months?

$\square$ Yes

$\square$ No

14) (if Y) Tell us about these recurring or regular flights.

- Frequency:

- Origin city:

- Destination city:

- Purpose: 


\section{Section 4: Attitudes}

15) Please complete the statement: For me to reduce business travel would be
Extremely bad 1
$2 \quad 3$
4
$\begin{array}{lll}5 & 6 & 7\end{array}$
Extremely good

16) Please complete the statement: For me to reduce business travel would be

$\begin{array}{llllllllll}\text { Extremely harmful } & 1 & 2 & 3 & 4 & 5 & 6 & 7 & \text { Extremely beneficial }\end{array}$

17) Please complete the statement: For me to reduce business travel would be

$\begin{array}{llllllllll}\text { Extremely worthless } & 1 & 2 & 3 & 4 & 5 & 6 & 7 & \text { Extremely valuable }\end{array}$

18) Please complete the statement: For me to reduce business travel would be

$\begin{array}{llllllllll}\text { Extremely unpleasant } & 1 & 2 & 3 & 4 & 5 & 6 & 7 & \text { Extremely pleasant }\end{array}$

19) Please complete the statement: For me to reduce business travel would be

$\begin{array}{llllllllll}\text { Extremely unenjoyable } & 1 & 2 & 3 & 4 & 5 & 6 & 7 & \text { Extremely enjoyable }\end{array}$

\section{Section 5: Subjective Norms}

20) Please rate your level of agreement: My peers at WRI would approve of my reducing business travel over the next 12 months.

$\begin{array}{lllllllll}\text { Strongly disagree } & 1 & 2 & 3 & 4 & 5 & 6 & 7 & \text { Strongly agree }\end{array}$

21) Please rate your level of agreement: My supervisors at WRI would approve of my reducing business travel over the next 12 months.

$\begin{array}{lllllllll}\text { Strongly disagree } & 1 & 2 & 3 & 4 & 5 & 6 & 7 & \text { Strongly agree }\end{array}$

22) Please rate your level of agreement: My professional network outside of WRI would approve of my reducing business travel over the next 12 months.

$\begin{array}{lllllllll}\text { Strongly disagree } & 1 & 2 & 3 & 4 & 5 & 6 & 7 & \text { Strongly agree }\end{array}$

23) Please rate your level of agreement: My friends and family would approve of my reducing business travel over the next 12 months.

$\begin{array}{lllllllll}\text { Strongly disagree } & 1 & 2 & 3 & 4 & 5 & 6 & 7 & \text { Strongly agree }\end{array}$

24) Please rate your level of agreement: It is expected of me that I reduce my business travel over the next 12 months.

$\begin{array}{lllllllll}\text { Strongly disagree } & 1 & 2 & 3 & 4 & 5 & 6 & 7 & \text { Strongly agree }\end{array}$

\section{Section 6: Behavioral Control}

25) Please complete the statement: For me to reduce business travel would be
Extremely impossible
1
23
$\begin{array}{lll}4 & 5 & 6\end{array}$
$7 \quad$ Extremely possible

26) Please rate your level of agreement: If I wanted to, I could reduce my business travel over the next 12 months.

$\begin{array}{lllllllll}\text { Strongly disagree } & 1 & 2 & 3 & 4 & 5 & 6 & 7 & \text { Strongly agree }\end{array}$


27) Please rate your level of agreement: I believe I have no control over reducing my business travel over the next 12 months.

$\begin{array}{lllllllll}\text { Strongly disagree } & 1 & 2 & 3 & 4 & 5 & 6 & 7 & \text { Strongly agree }\end{array}$

28) Please rate your level of agreement: It is mostly up to me whether I reduce my business travel over the next 12 months.

$\begin{array}{lllllllll}\text { Strongly disagree } & 1 & 2 & 3 & 4 & 5 & 6 & 7 & \text { Strongly agree }\end{array}$

\section{Section 7: Intention}

29) Please rate your level of agreement: I intend to reduce my business travel over the next 12 months.

$\begin{array}{lllllllll}\text { Strongly disagree } & 1 & 2 & 3 & 4 & 5 & 6 & 7 & \text { Strongly agree }\end{array}$

30) Please rate your level of agreement: I will try to reduce my business travel over the next 12 months.

$\begin{array}{lllllllll}\text { Strongly disagree } & 1 & 2 & 3 & 4 & 5 & 6 & 7 & \text { Strongly agree }\end{array}$

31) Please rate your level of agreement: I plan to reduce my business travel over the next 12 months.

$\begin{array}{lllllllll}\text { Strongly disagree } & 1 & 2 & 3 & 4 & 5 & 6 & 7 & \text { Strongly agree }\end{array}$

\section{Section 8: Self-Identity}

32) Please rate your level of agreement: Reducing my business travel is an important part of who I am.

$\begin{array}{lllllllll}\text { Strongly disagree } & 1 & 2 & 3 & 4 & 5 & 6 & 7 & \text { Strongly agree }\end{array}$

33) Please rate your level of agreement: I think of myself as the sort of person who would want to reduce my business travel.

$\begin{array}{lllllllll}\text { Strongly disagree } & 1 & 2 & 3 & 4 & 5 & 6 & 7 & \text { Strongly agree }\end{array}$

34) Please rate your level of agreement: I am not the type of person who would reduce my business travel.

$\begin{array}{lllllllll}\text { Strongly disagree } & 1 & 2 & 3 & 4 & 5 & 6 & 7 & \text { Strongly agree }\end{array}$

35) Please rate your level of agreement: I think of myself as being environmentally aware.

$\begin{array}{lllllllll}\text { Strongly disagree } & 1 & 2 & 3 & 4 & 5 & 6 & 7 & \text { Strongly agree }\end{array}$

36) Please rate your level of agreement: I think of myself as someone who is very concerned with environmental issues.
Strongly disagree 1
2
3
4
$5 \quad 6$
$7 \quad$ Strongly agree

37) Please rate your level of agreement: I would be embarrassed to be seen as having an environmentally friendly lifestyle.
Strongly disagree 1
2
4
$\begin{array}{lll}5 & 6 & 7\end{array}$
Strongly agree

38) Please rate your level of agreement: I want people who are important to me to think of me as someone who has an environmentally friendly lifestyle.
Strongly disagree 1
23
4
5
$6 \quad 7$
Strongly agree 


\section{Section 9: Travel Perceptions within WRI}

39) How do you think you compare to average WRI business travel frequency?

$\square \quad 0$-20th percentile (much less than average)

$\square$ 20th-40th percentile (less than average)

$\square$ 40th-60th percentile (about average)

$\square$ 60th-80th percentile (higher than average)

$\square$ 80th-100th percentile (much higher than average)

40) How do you think WRI's management and executive team travel compares to average WRI business travel frequency?

$\square \quad$ 0-20th percentile (much less than average)

$\square$ 20th-40th percentile (less than average)

$\square$ 40th-60th percentile (about average)

$\square$ 60th-80th percentile (higher than average)

$\square$ 80th-100th percentile (much higher than average)

41) How do you think your program/center/department/team travel compares to average WRI business travel frequency?

$\square$ 0-20th percentile (much less than average)

$\square$ 20th-40th percentile (less than average)

$\square$ 40th-60th percentile (about average)

$\square \quad$ 60th-80th percentile (higher than average)

$\square$ 80th-100th percentile (much higher than average)

42) How do you think WRI travel compares to peer organizations' business travel frequency?

$\square \quad 0$-20th percentile (much less than average)

$\square$ 20th-40th percentile (less than average)

$\square$ 40th-60th percentile (about average)

$\square$ 60th-80th percentile (higher than average)

$\square$ 80th-100th percentile (much higher than average)

\section{Section 10: Alternatives to Travel}

43) Did you use any alternatives to replace business travel flights in the last 12 months? Select as many that apply.

$\square$ Rail

$\square$ Car/van

$\square$ Bus

$\square$ Boat

$\square$ Virtual conference

$\square$ Other-write in (required): *

44) Did you use any alternatives to reduce business travel flying impacts in the last 12 months? Select as many that apply.

$\square$ Direct flights

$\square \quad$ Newer, fuel-efficient planes

$\square$ Send regional partner or colleague closer to destination in your place

$\square$ Send junior colleague (i.e., professional development) in your place

$\square$ Bundle destinations into multi-city trip

$\square$ Set budget or cap on travel

$\square$ Purchase carbon offsets

$\square$ Select specific airline for its sustainability efforts

$\square$ Other-write in (required): *

45) (if budget or cap above) Tell us more about your travel cap or budget. 
46) Please rank the alternatives to business travel flights by their positive environmental impact. Rank highly preferred for environmental reasons toward the top.
$\square \quad$ Virtual conferencing
$\square$ Rail or train
$\square$ Boat
$\square$ Bus
$\square \quad$ Car (high MPG, EV, or hybrid)
$\square \quad$ Car (average or lower MPG)
$\square$ Offsets

47) Please rank the alternatives to business travel flights by the feasibility as a replacement for your business travel trips. Rank more feasible options toward the top.
$\square \quad$ Virtual conferencing
$\square$ Rail or train
$\square$ Boat
$\square$ Bus
$\square \quad$ Car (high MPG, EV, or hybrid)
$\square \quad$ Car (average or lower MPG)
$\square$ Offsets

48) Please rank the alternatives to business travel flights by your willingness to replace your business travel trips. Rank options you are more willing to take toward the top.

$\square$ Virtual conferencing

$\square$ Rail or train

$\square$ Boat

$\square$ Bus

$\square$ Car (high MPG, EV, or hybrid)

$\square \quad$ Car (average or lower MPG)

$\square$ Offsets

49) Please suggest any other business travel flight alternatives not mentioned in previous questions (one suggestion per field).

- Suggestion 1:

- Suggestion 2:

- Suggestion 3 :

\section{Thank You!}




\section{APPENDIX B, COVID-19 TELEWORIKING AND AIR TRAVEL SURVEY (POST-SURVEY)}

\section{Welcome and thank you!}

The goal of this survey is to understand impacts of the COVID-19 pandemic on teleworking and air travel for work. Depending on your answers, the survey may take 5 to 15 minutes. Staff that telework and travel will have more questions. We greatly appreciate your patience and your insights on this survey. Please complete the survey by (DATE).

For any questions, contact (EMAIL).

\section{Experiences of Teleworking}

The following questions ask about effectiveness and quality of working from home and collaborating virtually before, during, and after the COVID-19 pandemic.

When questions ask about post-pandemic situations, please consider when operations have returned to normal after the end of the pandemic and any reopening transition.

1) Average days per week of working from home.*

$\begin{array}{lllllll}1 & 2 & 3 & 4 & 5 & 6 & 7\end{array}$

How many days per week did you work from home pre-pandemic:

How many days per week do you work from home currently:

How many days per week would you ideally work from home post-pandemic:

2) During the pandemic, how positive or negative is working from home for the following issues?

$\begin{array}{cccccc}1 \text { - Very } & 2 & 3-\text { Neutral } & 4 & \begin{array}{c}5 \text {-Very } \\ \text { Positive }\end{array} & \begin{array}{c}\text { NA/Don't } \\ \text { Know }\end{array}\end{array}$

Life-work balance

Commuting experience

Physical workspace

Quality of work

Quantity of work

Motivation

Collaboration with colleagues and/or

external partners

Overall job satisfaction 
3) Post-pandemic, how positive or negative would working from home your ideal number of days be for the following issues?

\begin{tabular}{|c|c|c|c|c|c|c|}
\hline & $\begin{array}{l}1 \text { - Very } \\
\text { Negative }\end{array}$ & 2 & 3 - Neutral & 4 & $\begin{array}{l}5 \text { - Very } \\
\text { Positive }\end{array}$ & $\begin{array}{l}\text { NA/Don't } \\
\text { Know }\end{array}$ \\
\hline \multicolumn{7}{|l|}{ Life-work balance } \\
\hline \multicolumn{7}{|l|}{ Commuting experience } \\
\hline \multicolumn{7}{|l|}{ Physical workspace } \\
\hline \multicolumn{7}{|l|}{ Quality of work } \\
\hline \multicolumn{7}{|l|}{ Quantity of work } \\
\hline \multicolumn{7}{|l|}{ Motivation } \\
\hline \multicolumn{7}{|c|}{$\begin{array}{l}\text { Collaboration with colleagues and/or } \\
\text { external partners }\end{array}$} \\
\hline Overall job satisfaction & & & & & & \\
\hline
\end{tabular}

4) Rate how your use of the following virtual platforms has changed since the pandemic.

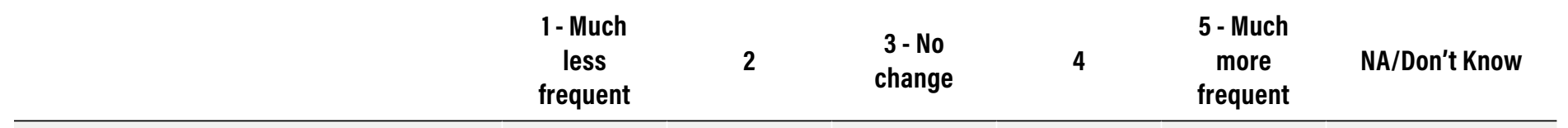

Virtual chats, document sharing on platforms such as Slack, Yammer, Microsoft Teams,

Smartsheet, Google docs, Sharepoint,

Dropbox, etc. (does NOT include video or audio communication)

Virtual audio/video meetings in which many speakers must collaborate (on platforms such as Microsoft Teams, Zoom, Bluejeans, Google Meet, Webex, etc.)

Large webinars, presentations, or virtual seminars 
5) Based on the most recent week's experience, rate the effectiveness of these categories of virtual collaborations or events:*

\begin{tabular}{|c|c|c|c|c|c|c|}
\hline & $\begin{array}{l}\text { 1-Very } \\
\text { Ineffective }\end{array}$ & 2 & 3 - Neutral & 4 & $\begin{array}{l}5 \text { - Very } \\
\text { Effective }\end{array}$ & $\begin{array}{l}\text { NA/Don't } \\
\text { Know }\end{array}$ \\
\hline \multicolumn{7}{|l|}{ Collaboration on document sharing or chat platforms } \\
\hline \multicolumn{7}{|l|}{$\begin{array}{l}\text { Small-group virtual meetings that require } \\
\text { collaboration among all participants (2-10 attendees, } \\
\text { no facilitator) }\end{array}$} \\
\hline \multicolumn{7}{|l|}{$\begin{array}{l}\text { Midsize-group virtual meetings that require } \\
\text { collaboration among all participants ( } 6-15 \text { attendees, } \\
\text { facilitator may be required) }\end{array}$} \\
\hline \multicolumn{7}{|l|}{$\begin{array}{l}\text { Large-group virtual meetings that require } \\
\text { collaboration across all participants ( } 15+\text { attendees, } \\
\text { when a facilitator is required) }\end{array}$} \\
\hline $\begin{array}{l}\text { Presentation events (webinars or seminars with many } \\
\text { attendees, but few primary speakers) }\end{array}$ & & & & & & \\
\hline
\end{tabular}

6) Please complete the following statements:

\begin{tabular}{llllll}
$\begin{array}{c}1 \text { - Very } \\
\text { Negative }\end{array}$ & 2 & 3 - Neutral & 4 & $\begin{array}{c}5 \text { - Very } \\
\text { Positive }\end{array}$ & $\begin{array}{c}\text { NA/Don't } \\
\text { Know }\end{array}$ \\
\hline
\end{tabular}

Working virtually during the pandemic compared to normal work pre-pandemic has been...

Expanding virtual working options when normal work resumes post-pandemic would be...

7) Please describe any additional benefits of working from home (as opposed to from the office):

8) Please describe any downsides to working from home and how your working from home experience could potentially be improved in the future.

\section{Forgone Air Travel for Work}

This section asks questions about air travel for work before the COVID-19 pandemic and what has changed due to the pandemic. In this section, "air travel for work" may also be referenced in shorthand by "air travel" or "work trip."

When questions ask about post-pandemic situations, please consider when operations have returned to normal, after the end of the pandemic and any reopening transition.

9) In a typical year, approximately how many work trips do you take? Please enter an estimated number of trips, counting the destinations and not any connecting flights. For example, a round trip between London and DC and any layovers should still counts as 1. For multi-city trips, count the destination cities. A one-way flight from $D C$ to a conference in London, followed by a flight to Amsterdam for a meeting before returning to DC would count as two trips. Do not factor in disruptions due to the pandemic. 
10) In a typical year, about what percentage of flights for work are short-, medium-, and long-haul?

$\%$ Short-haul flights ( $0-3$ hours):

$\%$ Medium-haul flights (3-6 hours):

$\%$ Long-haul flights (6+ hours):

11) Please select the top reasons for your air travel for work. Select up to 2.

$\square$ Conference/workshop participation

$\square$ Fund raising/development/advancement

$\square$ Relationship building/establishment

$\square$ Project management

$\square$ Speaking engagement

$\square$ Data collection/research

Other-Write in:

12) Have you forgone air travel for work as a result of the pandemic?*

$\square$ Yes

$\square$ No

13) From the period of January 2020 to June 2020, how many work trips will have been forgone?

14) What portion of the forgone air travel has been or will be replaced by virtual communications? Please estimate to the nearest \%.

15) What portion of the forgone travel may still take place in the future, even if there has been a virtual alternative? Please estimate to the nearest \%.

16) Can you tell us more about how forgone air travel may have affected you, your colleagues, or your work?

\section{Future Air Travel for Work}

This section asks questions about your perceptions of air travel for work after the COVID-19 pandemic. When questions ask about post-pandemic situations, please consider when operations have returned to normal after the end of the pandemic and any reopening transition.

"Air travel for work" may also be referenced in shorthand by "air travel" or "work trip."

17) Please complete the statements.

1 - Extremely
harmful $\quad 2 \quad 3$ - Neutral $\quad 4 \quad \begin{gathered}5 \text { - Extremely } \\ \text { beneficial }\end{gathered} \begin{gathered}\text { NA/Don't } \\ \text { Know }\end{gathered}$

For me to reduce air travel for work

would be

For my organization to reduce air travel

for work would be 


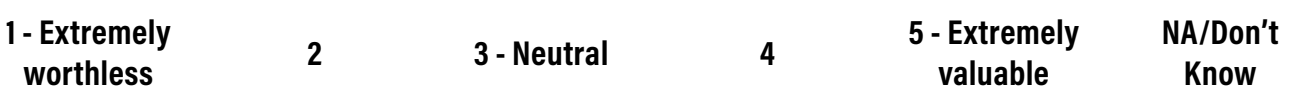

For me to reduce air travel for work would be

\section{1 - Extremely} impossible
2

For me to reduce air travel for work would be

18) Please rate your level of agreement with the following statements:
2
3 - Neutral

3 - Neutral
4

4

$\begin{array}{cc}5 \text { - Extremely } & \text { NA/Don't } \\ \text { possible } & \text { Know }\end{array}$

\begin{tabular}{cccccc}
$\begin{array}{c}1 \text { - Strongly } \\
\text { Disagree }\end{array}$ & 2 & 3 - Neutral & 4 & $\begin{array}{c}5 \text { - Strongly } \\
\text { Agree }\end{array}$ & $\begin{array}{c}\text { NA/Don't } \\
\text { Know }\end{array}$ \\
\hline
\end{tabular}

I would be embarrassed to be seen as

having a large carbon footprint.

I want to be seen as someone who frequently travels for work.

My organization would lose credibility if seen as having a large carbon footprint.

My organization considers travel to be essential to achieving its mission.

My organization has the type of culture that would encourage reducing air travel for work.

People in my organization like being seen as frequent business travelers.

My supervisor(s) would support me reducing my air travel for work in the future.

I believe it is mostly my decision whether I reduce air travel for work in the future. 


\begin{tabular}{|c|c|c|c|c|c|c|}
\hline & $\begin{array}{l}\text { 1- Strongly } \\
\text { Disagree }\end{array}$ & 2 & 3 - Neutral & 4 & $\begin{array}{l}5 \text { - Strongly } \\
\text { Agree }\end{array}$ & $\begin{array}{l}\text { NA/Don't } \\
\text { Know }\end{array}$ \\
\hline \multicolumn{7}{|l|}{$\begin{array}{l}\text { I would be embarrassed to be seen as having an } \\
\text { environmentally friendly lifestyle. }\end{array}$} \\
\hline \multicolumn{7}{|l|}{$\begin{array}{l}\text { My peers at WRI would approve of my reducing air } \\
\text { travel for work. }\end{array}$} \\
\hline \multicolumn{7}{|l|}{$\begin{array}{l}\text { My supervisors at WRI would approve of my reducing } \\
\text { air travel for work. }\end{array}$} \\
\hline \multicolumn{7}{|l|}{$\begin{array}{l}\text { My professional network outside of WRI would } \\
\text { approve of my reducing air travel. }\end{array}$} \\
\hline $\begin{array}{l}\text { Post-pandemic, I intend to reduce my air travel for } \\
\text { work. }\end{array}$ & & & & & & \\
\hline
\end{tabular}

19) How do you think you compare to average WRI business travel frequency?

$\square \quad 0$-20th percentile (much less than average)

$\square \quad$ 20th-40th percentile (less than average)

$\square$ 40th-60th percentile (about average)

$\square$ 60th-80th percentile (higher than average)

$\square$ 80th-100th percentile (much higher than average)

20) Post-pandemic, how do you think reduced air travel will affect the following?

\begin{tabular}{|c|c|c|c|c|c|c|}
\hline & $\begin{array}{l}1 \text { - Very } \\
\text { Negative }\end{array}$ & 2 & 3 - Neutral & 4 & $\begin{array}{l}5 \text { - Very } \\
\text { Positive }\end{array}$ & $\begin{array}{l}\text { NA/Don't } \\
\text { Know }\end{array}$ \\
\hline Life-work balance & & & & & & \\
\hline Quality of work & & & & & & \\
\hline Quantity of work & & & & & & \\
\hline Motivation & & & & & & \\
\hline $\begin{array}{l}\text { Collaboration with colleagues and/or } \\
\text { external partners }\end{array}$ & & & & & & \\
\hline Overall job satisfaction & & & & & & \\
\hline
\end{tabular}

21) What other impacts would reduced air travel for work have for you or your organization (e.g., leadership development, equity, staff recruitment or retention, etc.)? 
22) Please rate the effectiveness of replacing air travel with virtual communications in the following situations:

\begin{tabular}{|c|c|c|c|c|c|c|}
\hline & $\begin{array}{c}1 \text { - Very } \\
\text { Ineffective }\end{array}$ & 2 & 3 - Neutral & 4 & $\begin{array}{l}5 \text { - Very } \\
\text { Effective }\end{array}$ & $\begin{array}{c}\text { NA/Don't } \\
\text { Know }\end{array}$ \\
\hline \multicolumn{7}{|c|}{ Conference/workshop participation } \\
\hline \multicolumn{7}{|c|}{ Fundraising/development/advancement } \\
\hline \multicolumn{7}{|c|}{ Relationship building/establishment } \\
\hline \multicolumn{7}{|l|}{ Project management } \\
\hline \multicolumn{7}{|l|}{ Speaking engagement } \\
\hline Data collection/research & & & & & & \\
\hline
\end{tabular}

23) Please tell us what organizational improvements would support replacing future air travel for work with virtual communications.

24) Would you use any air-travel alternatives post-pandemic? Select as many that apply.
$\square$ Rail
$\square$ Car/van
$\square$ Bus
$\square$ Boat
$\square$ Other-Write in:
$\square \quad$ None of the above

25) Please select the top three factors that would help promote air-travel alternatives (e.g., rail, virtual communication, etc.) at your workplace in the future.
$\square$ Financial support from your work to subsidize additional cost of flight alternatives (e.g., rail, ground, or sea transportation)
$\square$ Support from your supervisor/department in terms of flexibility for increased journey time when taking flight-alternative travel
$\square$ Recognition by funders of the added costs and demands from flight-alternative travel
$\square$ Rewards or incentives for using flight-alternative travel
$\square$ Improvements in speed of flight-alternative travel
$\square$ More information about flight-alternative travel
$\square$ Other staff and peers taking flight-alternative travel

26) Compared to your thoughts pre-pandemic, how do you now feel about reducing business air travel in terms of impact on your work?

\begin{tabular}{|c|c|c|c|c|c|c|}
\hline & $\begin{array}{l}\text { 1- Strongly } \\
\text { Disagree }\end{array}$ & 2 & 3 - Neutral & 4 & $\begin{array}{l}5 \text { - Strongly } \\
\text { Agree }\end{array}$ & $\begin{array}{l}\text { NA/Don't } \\
\text { Know }\end{array}$ \\
\hline $\begin{array}{l}\text { Reducing business travel is more feasible and can be } \\
\text { done more successfully than I thought. }\end{array}$ & & & & & & \\
\hline $\begin{array}{l}\text { Reducing business travel is as feasible and can be as } \\
\text { successful as I previously thought. (There has been } \\
\text { no change in my thinking on this issue.) }\end{array}$ & & & & & & \\
\hline $\begin{array}{l}\text { Reducing business travel is less feasible and can be } \\
\text { done less successfully than I previously thought. }\end{array}$ & & & & & & \\
\hline
\end{tabular}


27) If your organization (WRI) initiates an air travel-reduction strategy post-pandemic, how much would you individually reduce your air travel?

I would commit to reduce my air travel for work by percent compared to pre-pandemic levels.

Please enter a percent (0-100\%) reduction from a typical future year compared to a typical past year of air travel for work. You previously entered that you take about [question ('value'), id='102'] trips in a typical year.

If you do not expect to reduce air travel or you expect to increase air travel post-pandemic, please enter 0.

\section{Demographics}

We use demographic information in aggregate and for analysis only. The demographic information collected will only be accessible to a handful of survey organizers, some of whom are outside our organization. Every effort will be made to maintain privacy and security.

28a) What program/center/department are you in? (DROP-DOWN WRI LIST)

28b) What level do you belong to in your institution?

$\square$ Intern

$\square$ Junior (e.g., coordinator, assistant, analyst)

$\square \quad$ Mid-level (e.g., coordinator II, associate, manager)

$\square$ Senior (e.g., director, senior fellow, management team)

$\square$ Executive (e.g., executive team, board member)

$\square \quad$ Other (e.g., secondee, temporary, consultant)

29) What is your primary office assignment or affiliation? (DROP-DOWN WRI LIST)

30) Where are you working from during the pandemic?

$\square$ Home

$\square$ Office

$\square$ Other-Write in:

31) Do you have caregiving responsibilities at home?

Caregiving responsibilities include but are not limited to assisting other people with personal care, food preparation, health care, mobility and transportation, and emotional support.

$\square$ Yes

$\square$ No

32) Would you be willing to answer a few more demographic questions?*

$\square$ Yes

$\square$ No

33) (if $Y$ ) What is your gender?

$\square$ Female

$\square$ Male

$\square$ Nonbinary

$\square$ Prefer to self-describe: 
38) (if $Y$ ) What is your age group?
$\square$ 16-30 years old
$\square \quad 31-45$ years old
$\square \quad 46-60$ years old
$\square$ 61+
$\square$ Prefer not to say

39) (if Y) Are there children living in your household?

$\square$ Yes

$\square$ No

40) (if Y) Including yourself, how many people currently live in your household?

41) (if $Y$ ) Do you own or rent your current residence?

$\square$ Own

$\square$ Rent

$\square$ Other-Write in:

\section{Thank You!}

Thank you for taking our survey. Your response is very important to us. If you have any questions, feel free to contact (email). 


\section{APPENDIX C. PRE-SURVEY RESPONSETABLE}

\section{Profile of Pre-Survey Respondents, Compared to Overall WRI Profile}

\begin{tabular}{|c|c|c|c|c|}
\hline SEGMENT & $\begin{array}{r}\text { INSTITUTIONAL } \\
\text { TOTAL }^{\mathrm{a}}(\mathrm{N})\end{array}$ & $\begin{array}{r}\text { INSTITUTIONAL } \\
\text { TOTAL (\%) }\end{array}$ & $\begin{array}{r}\text { SURVEY } \\
\text { RESPONDENTS (N) }\end{array}$ & $\begin{array}{r}\text { SURVEY } \\
\text { RESPONDENTS (\%) }\end{array}$ \\
\hline Total & 1077 & $100 \%$ & 140 & $100 \%$ \\
\hline \multicolumn{5}{|l|}{ Level of Employment } \\
\hline Junior & 336 & $31 \%$ & 29 & $21 \%$ \\
\hline Mid-level & 359 & $33 \%$ & 81 & $58 \%$ \\
\hline Senior & 120 & $11 \%$ & 26 & $19 \%$ \\
\hline Other (e.g., interns, secondees, consultants) & 262 & $24 \%$ & 4 & $3 \%$ \\
\hline \multicolumn{5}{|l|}{ Location } \\
\hline WRI U.S. & 521 & $48 \%$ & 90 & $64 \%$ \\
\hline WRI Africa & 34 & $3 \%$ & 11 & $8 \%$ \\
\hline WRI Brasil & 68 & $6 \%$ & 2 & $1 \%$ \\
\hline WRI China & 33 & $3 \%$ & 9 & $6 \%$ \\
\hline WRI Europe & 46 & $4 \%$ & 17 & $12 \%$ \\
\hline WRI India & 148 & $14 \%$ & 3 & $2 \%$ \\
\hline WRI Indonesia & 144 & $13 \%$ & 0 & $0 \%$ \\
\hline WRI Mexico & 74 & $7 \%$ & 8 & $6 \%$ \\
\hline WRI Other Office & 9 & $1 \%$ & 0 & $0 \%$ \\
\hline All International Offices & 556 & $52 \%$ & 50 & $36 \%$ \\
\hline
\end{tabular}

Note: anstitutional staff numbers come from human resources data from October 2019. 


\section{APPENDIX D. POST-SURVEY RESPONSE TABLE}

\section{Profile of Post-Survey Respondents, Compared to Overall WRI Profile}

\begin{tabular}{|c|c|c|c|c|}
\hline SEGMENT & $\begin{array}{r}\text { INSTITUTIONAL } \\
\text { TOTAL }^{\text {a }}(\mathrm{N})\end{array}$ & $\begin{array}{l}\text { INSTITUTIONAL } \\
\text { TOTAL (\%) }\end{array}$ & $\begin{array}{r}\text { SURVEY } \\
\text { RESPONDENTS (N) }\end{array}$ & SURVEY RESPONDENTS (\%) \\
\hline Total & 1322 & $100 \%$ & 457 & $35 \%$ \\
\hline \multicolumn{5}{|l|}{ Level of Employment } \\
\hline Junior & 384 & $29 \%$ & 114 & $25 \%$ \\
\hline Mid-level & 429 & $32 \%$ & 225 & $49 \%$ \\
\hline Senior & 128 & $10 \%$ & 80 & $18 \%$ \\
\hline Other (e.g., interns, secondees, consultants) & 340 & $26 \%$ & 38 & $8 \%$ \\
\hline \multicolumn{5}{|l|}{ Location } \\
\hline WRI U.S. & 552 & $42 \%$ & 192 & $42 \%$ \\
\hline WRI Africa & 43 & $3 \%$ & 20 & $4 \%$ \\
\hline WRI Brasil & 63 & $5 \%$ & 30 & $7 \%$ \\
\hline WRI China & 35 & $3 \%$ & 22 & $5 \%$ \\
\hline WRI Europe & 56 & $4 \%$ & 28 & $6 \%$ \\
\hline WRI India & 206 & $16 \%$ & 77 & $17 \%$ \\
\hline WRI Indonesia & 247 & $19 \%$ & 68 & $15 \%$ \\
\hline WRI Mexico & 85 & $6 \%$ & 10 & $2 \%$ \\
\hline WRI Other Office & 35 & $3 \%$ & 5 & $1 \%$ \\
\hline All International Offices & 770 & $58 \%$ & 260 & $57 \%$ \\
\hline
\end{tabular}

Note: ${ }^{\text {In }}$ stitutional staff numbers come from human resources data from August 2020. 


\section{APPENDIX E, TRIP FREQUENCY BY LEVEL (PRE- AND POST-SURVEY)}

\begin{tabular}{|l|r|r|r|r|}
\hline \multirow{2}{*}{ SEGMENT } & \multicolumn{2}{|c|}{ PRE-SURVEY } & \multicolumn{2}{c|}{ POST-SURVEY } \\
\cline { 2 - 5 } & N & Avg. flights per person & N & Avg. flights per person \\
\hline All staff (140) & 140 & 6.67 & 457 & 6.26 \\
\hline Senior (26) & 26 & 10.61 & 80 & 12.16 \\
\hline Mid-level and junior (110) & 110 & 5.37 & 339 & 5.12 \\
\hline Mid-level (81) & 81 & 5.63 & 225 & 5.70 \\
\hline Junior & --- & 4.66 & 114 & 3.98 \\
\hline Male & --- & --- & 172 & 8.13 \\
\hline Female & --- & --- & 266 & 5.20
\end{tabular}

\section{APPENDIX F. SUGGESTIONS FROM STAFF TO SUPPORT REPLACING AIR TRAVEL WITH VIRTUAL COMMUUNICATIONS, ORDERED BY FREQUENCY OF APPEARANCE}

\section{CHANGING BEHAVIOR AND PRACTICES}

Ecosystem change: Engage partners and donors to change how sector operates

WRI culture change: Cultivate inclusive best practices for virtual collaboration (e.g., put more effort into virtual event planning; improve documentation of meetings and dissemination of minutes; use more written communication to help staff in different time zones).

Optimize proposals: Structure proposals and budgets to specify which activities will be conducted virtually and lay out benefits of reducing travel (e.g., more money directed toward webinars that can reach more people).

Leading by example: Institute an organizational mandate to reduce air travel for work and have senior leaders reduce their own travel.

Strengthen collaboration across WRI's international network: Share more responsibilities with international office staff located within the region of work and encourage temporary relocations.

PROVIDING BETTER INFRASTRUCTURE

More training and support: Provide more training for using virtual communications and more support for virtual events (e.g., hire more event support staff for large webinars, etc.).

Facilities for virtual communications: Install dedicated physical spaces for teleconferencing in WRI offices (e.g., soundproofed rooms with cameras and locks).

Access to better software: For example, Zoom Pro.

Access to better equipment: Provide staff with equipment like monitors and noise-canceling headphones.

Access to better internet: Upgrade home internet plans for staff.

Total Number of Staff Providing Suggestions: 62 


\section{APPENDIX G. ENHANCED TRAVEL REQUEST FORM (SAMPLE)}

\section{Flight Request Details}

1. Flight Requested:

2. $\mathrm{CO}_{2}$ emissions produced by this trip:

3. Your travel reduction goal for this FY:

\section{Emissions Justification}

\section{BOX G-1 | TRAVEL PRIORITIES}

- Relationship building

- Connecting to new partners/opportunities

- Data collection

- Project management

- Professional development, especially for junior staff and staff with no or low-frequency travel

1. Which specific organizational travel priorities (See text Box G-1), does this trip advance?

2. Why can't this trip be substituted by a virtual event?

3. Are other team members attending this event?

4. If you answered yes to Question 3, what is your role at the event, and why is the additional trip needed?

5. Is there an opportunity for a regional colleague to attend in your place?

Staff Signature

Supervisor Signature 


\section{APPENDIX H. BEHAVIORALLY DESIGNED EMAIL FROM WRI PILOT, JANUARY-FEBRUARY 2020}

Emails to staff who traveled had four main behavioral features in the sample below.

1. Leadership signal: Emails sent from the $\mathrm{COO}$, a respected member of the executive team who had himself reduced his travel significantly

2. Feedback: Personalized flight impact information, including number of trips, $\mathrm{CO}_{2}$ emissions in $\mathrm{kg}$, and $\mathrm{CO}_{2}$ emissions translated into pounds $/ \mathrm{kg}$ of coal burned

3. Norm message: Comparisons with peers along with an injunctive norm symbol (happy or sad face)

4. Pledge: A prompt to take a pledge to reduce travel

Sophie, how do your travel emissions compare to your WRI peers? We crunched your numbers.

As WRI staff, we've joined this organization because we care about the environment. Air travel is particularly high-impact, making up roughly a quarter of our total GHG emissions.

:- Your total emissions from work-related air travel last year were $6,812 \mathrm{~kg} \mathrm{CO} 2 \mathrm{e}$, which are equivalent to 5,442 pounds $(2,469 \mathrm{~kg})$ of coal burned.

$\because$ Your GHG emissions are $42 \%$ higher compared to the average for WRI staff in similar positions

(Associates / Managers / Fellows).

Period: Jan-Nov 2019

Total Miles Traveled: $28,024(45,100 \mathrm{~km})$

Totals Trips: 8

Total Hours Lost to Travel: 85

From the recent travel survey, about $90 \%$ of staff wish to reduce GHG emissions from air travel. While reducing travel seems daunting, it's not impossible! By rethinking how I travel and incorporating more frequent virtual communications, I managed to reduce my air travel by $50 \%$ since 2016 and now only travel 2-4 times a year. The $\mathbf{2 0 2 0}$ "super year" can be a fresh start for reducing our environmental impact: I encourage you to set a reduction goal for yourself by the end of January. For questions, reach out to SustainabilityCoreTeam@wri.org.

Steve Barker

CMA CFM MBA

VP CFOO - World Resources Institute

Set your reduction goal for 2020 by Fri, Jan 31 and stay tuned for monthly updates.

I will not travel by air in 2020

highest ambition

other

follow up with me
$50 \%$ reduction

high ambition
$30 \%$ reduction

aligned with science-based targets 
1. Cost and flight from WRI administrative booking software from MarchDecember 2020 during pandemic and compared to same MarchDecember 2019 period pre-pandemic.

2. Hours of flights estimated using mileage data from WRI administrative booking software and average commercial flights.

3. The target range shown in Figure 1 shows the range of history of all targets and pledges submitted by countries to United Nations Framework Convention on Climate Change (UNFCCC) since the 1997 Kyoto Protocol through the NDCs as part of the Paris Agreement. Shown with the max and min emissions growth projections from Climate Action Tracker (2020), these targets are insufficient to achieve a $1.5^{\circ}-2^{\circ} \mathrm{C}$ goal.

4. A carbon offset or credit is defined as a unit that funds the reduction of one metric tonne of carbon from the environment.

5. For more on carbon offsets, see Can You Really Negate Your Carbon Emissions? (Irfan 2020).

6. Extrapolated from the UN estimate of $918 \mathrm{M} \mathrm{mt} \mathrm{CO}$ and scales for $10 \%$ $12 \%$ of demand. Attribution of carbon emissions impact from business travel is an area ripe for additional research. The equivalency was calculated using EPA's carbon calculator: https://www.epa.gov/energy/ greenhouse-gas-equivalencies-calculator.

7. Organizational estimates are based on voluntary reporting of annual GHG emissions inventories, either on their own websites or through $\mathrm{CDP}, \mathrm{GRI}$, or other aggregation sites.

8. WRI's online booking system captures all travel from WRI's largest office (U.S.) and WRI China, which together represent 44\% of WRI's staff. The system also captures some travel from WRI Europe and WRI Africa.

9. Total global staff count source: WRI HR, in 2019 total was 1,062

10. Hours estimated by dividing the total air miles traveled (reported by administrative data) by the average speed of a commercial jet.

11. Aviation daily activity is defined as total number of departing flights.

12. Calculated per EPA's carbon calculator: https://www.epa.gov/energy/ greenhouse-gas-equivalencies-calculator.

13. The other top targets include a $20 \%$ reduction of emissions from goods \& services (scope 3 ) and $50 \%$ reduction of emissions from purchased electricity (scope 2) by 2020. At the time of this paper, more ambitious science-based targets for emissions reduction are being set for 2030. (See wri.org/sustainability for more on GHG emissions data and WRI targets)
14. This paper captures WRI-specific findings. A group of NGOs through the SMRT network surveyed 8 of their member organizations between July and November 2020. Full SMRT data includes over 1,300 responses in 8 organizations; a summary of results is expected to be published in 2021.

15. See Kahneman, Daniel. Thinking, Fast and Slow. New York: Farrar, Straus, and Giroux, 2011.

16. Sometimes barriers are referred to as hassle factors or blocked channels.

17. Use of the booking system is only mandatory for staff based in WRI's U.S. and China offices. As many staff outside of the U.S. and China book their travel elsewhere, the survey was sent to a disproportionate number of U.S. and China-based staff.

18. Instead of asking respondents to report individual flight legs, which is what the flight data capture, the survey asked respondents to report 'work trips.' A single work trip was defined by the destination and purpose of the trip. For example, a round trip from Beijing to Washington, D.C. with a layover in London was considered one work trip. However, a multi-city trip from Beijing to Washington, D.C. to New York City to Beijing was considered two work trips if the traveler conducted business in both Washington and New York. This definition of 'work trip' was used because respondents were more likely to recall their travel by destination and purpose instead of by individual flight legs taken.

19. Both surveys also asked about commuting behaviors, and the PostSurvey asked about working from home experiences.

20. Administrative data defines a flight as each individual flight leg. Thus, a one-way journey from Beijing to Washington D.C. with a layover in London is recorded as two flights. WRI's methods for calculating the emissions associated with each flight is documented in the WRI Greenhouse Gas Reporting Methodology.

21. Senior staff include: Directors, Management Team, and Executive Team

22. Both Pre- and Post-Surveys asked staff to report on flight frequency in the last year. Reported trips per year were similar (less than $1 \%$ difference) between the two surveys. We therefore use the Post-Survey flight frequency data in the Paper as it is more recent.

23. The data reported reflect changes from pre- to post-COVID surveys using the full samples. We also ran a subsample analysis on a longitudinal sample $(n=45)$ of the same staff who took the pre and post survey to explore how the same staff viewed changes over time and to detect any significant variance between the subsample and full sample. No significant differences were found.

24. In a more ambitious leadership initiative, several corporations have tied executive salary and bonuses to overall GHG emissions performance (Ceres 2014), 
REFERENCES

Allcott, Hunt, and Todd T. Rogers. 2012. "How Long Do Treatment Effects Last? Persistence and Durability of a Descriptive Norms Intervention's Effect on Energy Conservation." HKS Faculty Research Working Paper Series. Cambridge, MA: John F. Kennedy School of Government, Harvard University. https://dash.harvard. edu/handle/1/9804492.

Borko, Seth, Wouter Geerts, and Haixia Wang. 2020. The Travel Industry Turned Upside down: Insights, Analysis and Actions for Travel Executives. McKinsey \& Company with Skift Research. https://www.mckinsey.com/ /media/mckinsey/ industries/travel\%20transport\%20and\%20logistics/our\%20insights/the\%20 travel\%20industry\%20turned\%20upside\%20down\%20insights\%20analysis\%20 and\%20actions\%20for\%20travel\%20executives/the-travel-industry-turnedupside-down-insights-analysis-and-actions-for-travel-executives.pdf.

Bouye, Mathilde, Alexander Tankou, and Delfina Grinspan. 2019. "Growing Momentum for Just Transition: 5 Success Stories and New Commitments to Tackle Inequality through Climate Action." Blog. August 6, 2019. World Resources Institute. https://www.wri.org/blog/2019/08/growing-momentum-justtransition-5-success-stories-and-new-commitments-tackle.

Cameron, Doug, and Eric Morath. 2021. "COVID-19's Blow to Business Travel Is Expected to Last for Years." Wall Street Journal, January 17. https://www.wsj. com/articles/covid-19-pandemics-impact-on-business-travel-hitting-localeconomies-11610879401.

Ceres. 2014. "Gaining Ground: Corporate Progress on the Ceres Roadmap for Sustainability." https://www.ceres.org/resources/reports/gaining-groundcorporate-progress-ceres-roadmap-sustainability. Accessed April 2, 2021.

Certify. 2021. "Understanding the Average Cost of Business Travel." https://www. certify.com/Infographic-TheAverageCostOfBusinessTravel.aspx. Accessed June 24.

Chamorro-Premuzic, Tomas. 2015. "The Health Risks of Business Travel." Harvard Business Review, November 3. https://hbr.org/2015/11/the-health-risks-ofbusiness-travel

Climate Action Tracker. 2021. "International Aviation." https:// climateactiontracker.org/sectors/aviation/. Accessed June 24.

El Takriti, Sammy, and Nikita Pavlenko. 2017. Mitigating International Aviation Emissions: Risks and Opportunities for Alternative Jet Fuels. International Council on Clean Transportation. https://theicct.org/publications/mitigatinginternational-aviation-emissions-risks-and-opportunities-alternative-jet. Accessed November 30, 2020 .

Graver, Brandon, Kevin Zhang, and Dan Rutherford. 2019. "CO Emissions from Commercial Aviation, 2018." Working Paper 2019-16. Washington, DC: International Council on Clean Transportation.

Grous, Alexander. 2017. "Managing Every Mile: How to Deliver Greater Return on Investment from Travel and Expense." Amadeus. https://amadeus.com/en/ insights/white-paper/managing-every-mile-how-to-deliver-greater-return-oninvestment\#modal1728895156. Accessed August 4, 2021.

IATA (International Air Transport Association). 2021. "2020 Worst Year in History for Air Travel Demand." IATA. https://www.iata.org/en/pressroom/pr/2021-02-0302/.

ICA0. 2019. 2019 Environmental Report, Aviation and Environment. Montreal, Canada: United Nations. https://www.icao.int/environmental-protection/pages/ envrep2019.aspx.

Irfan, Umair. 2020. "Can You Really Negate Your Carbon Emissions? Carbon Offsets, Explained." Vox. https://www.vox.com/2020/2/27/20994118/carbonoffset-climate-change-net-zero-neutral-emissions.

Kahneman, Daniel. 2011. Thinking, Fast and Slow. New York: Farrar, Straus, and Giroux.
Kamins, Alla, Eliot Metzger, Lu Miao, Talia Rubnitz, Katerina Trostmann, Richard Waite, and Shengyin Xu. 2016. Stories from the WRI Sustainability "Living Lab." Washington, DC: World Resources Institute.

Katzev, R., and T. Wang. 1994. "Can Commitment Change Behavior? A Case Study of Environmental Actions." Journal of Social Behavior and Personality 9 (1): 13.

Kharina, Anastasia, and Dan Rutherford. 2015. "Fuel Efficiency Trends for New Commercial Jet Aircraft: 1960 to 2014." International Council on Clean Transportation. https://theicct.org/publications/fuel-efficiency-trends-newcommercial-jet-aircraft-1960-2014. Accessed April 2, 2021.

Le Quéré, Corinne, Robert B. Jackson, Matthew W. Jones, Adam J.P. Smith, Sam Abernethy, Robbie M. Andrew, Anthony J. De-Gol, et al. 2020، "Temporary Reduction in Daily Global $\mathrm{CO}_{2}$ Emissions during the COVID-19 Forced Confinement." Nature Climate Change 10 (7): 647-653. doi:10.1038/s41558-0200797-X.

Lewin, Kurt. 1943. "Defining the 'Field at a Given Time."' Psychological Review 50: 292-310.

Liu, Zhu, Philippe Ciais, Zhu Deng, Ruixue Lei, Steven J. Davis, Sha Feng, Bo Zheng, et al. 2020. "Near-Real-Time Monitoring of Global CO Emissions Reveals the Effects of the COVID-19 Pandemic." Nature Communications 11 (1): 5172. doi:10.1038/s41467-020-18922-7.

McCartney, Scott. 2020. "The Covid Pandemic Could Cut Business Travel by 36\%-Permanently." Wall Street Journal, December 1, 2020. https:// www.wsj.com/articles/the-covid-pandemic-could-cut-business-travel-by36permanently-11606830490.

Ritchie, Hannah. 2020. "Climate Change and Flying: What Share of Global CO Emissions Come from Aviation?" Data and Tools. Our World in Data. https:// ourworldindata.org/co2-emissions-from-aviation. Accessed November 13, 2020.

Ross, Lee, and Richard E. Nisbett. 1991. The Person and the Situation: Perspectives of Social Psychology. London: Pinter \& Martin Ltd.

Sheeran, P. 2005. "Intention-Behavior Relations: A Conceptual and Empirical Review." European Journal of Social Psychology 12: 1-36.

Sheeran, $P_{1}$, and C. Abraham. 2003. "Mediator of Moderators: Temporal Stability of Intention and the Intention-Behavior Relation." Personality and Social Psychology Bulletin 29 (2): 205-215.

Sherwood, S.C., M.J. Webb, J.D. Annan, K.C. Armour, P.M. Forster, J.C. Hargreaves, G Hegerl, et al. 2020. "An Assessment of Earth's Climate Sensitivity Using Multiple Lines of Evidence." Reviews of Geophysics 58, no. 4: e2019RG000678. https://doi. org/10.1029/2019RG000678

Stalnaker, Tom, and Khalid Usman. 2021. Airline Economic Analysis 2020-2021. Oliver Wyman. https://www.oliverwyman.com/content/dam/oliver-wyman/v2/ AEA\%202021_Master_Final2.pdf.

Trondent Development Corp. 2019. "Business Travel by the Numbers." Trondent Development Corp. https://www.trondent.com/business-travel-statistics/. Accessed November 16, 2020.

UCS (Union of Concerned Scientists). 2020. "Each Country's Share of $\mathrm{CO}_{2}$ Emissions." https://www.ucsusa.org/resources/each-countrys-share-co2emissions. Accessed April 2, 2021.

WRI. 2021. "Mission and Values." https://www.wri.org/about/mission-values. Accessed June 24

UNWTO (United Nations World Tourism Organization). 2020. "The Impact of COVID-19 on Tourism." https://webunwto.s3.eu-west-1.amazonaws.com/s3fspublic/2020-08/UN-Tourism-Policy-Brief-Visuals.pdf.

Zheng, Xinyi Sola, Brandon Graver, and Dan Rutherford. 2019. "Despite Investments in More Efficient Aircraft by U.S. Airlines, Demand Growth Continues to Outpace Fuel Efficiency Gains." International Council on Clean Transportation. https://theicct.org/news/despite-investments-more-efficient-aircraft-usairlines-demand-growth-continues-outpace-fuel. Accessed November 13, 2020. 


\section{ACKNOWLEDGMENTS}

Thank you to the many contributors, reviewers, editors, and designers who shared their time, insights, and creativity.

Contributors: Kate Esbenshade, Shannon Hall

WRI Reviewers: Daniel Vennard, Shailesh Shreedhan, Kelly Levin, Anne Maassen, Kirana Agustina, Nanda Noor

External Reviewers: Stephen Roll, Dan Salzer (The Nature Conservancy), Maria McCain (Natural Resources Defense Council)

Production: Romain Warnault, Caroline Taylor, and Billie Kanfer.

Editor: Carlos Munoz Pina

\section{ABOUT THE AUTHORS}

Mindy Hernandez is an applied behavioral researcher focusing on pro-social behaviors like energy conservation, voting, and medication adherence. Mindy is the behavioral science adviser at WRI. Previously, she worked as a liaison to the White House's Social and Behavioral Science Team for the U.S. Agency for International Development, as a fellow for the Federal Office of Evaluation Sciences, and as a senior researcher with ideas42. Mindy holds a Master's degree in Public Policy from Princeton University.

Shengyin Xu is the global sustainability manager at World Resources Institute. She helps WRI "walk the talk" on sustainability and leads initiatives to measure, reduce, and communicate the environmental impact of its operations. This includes conducting greenhouse gas emissions inventories; strategizing and implementing impact carbon-reduction projects; leveraging internal carbon pricing; and engaging staff, partners, and external stakeholders on topics such as waste, the circular economy, commuting, and food. She has over 15 years' experience helping nonprofits, museums, and universities adopt organizational sustainability practices.

Lucas Toh is a sustainability professional with substantial experience in conducting and reporting greenhouse gas inventories, devising and implementing sustainability strategies, and engaging stakeholders. He previously worked at WRI as a research analyst and program specialist.

Dr. Sophie Attwood is a senior behavioral scientist specializing in changing health and sustainability related behaviors. Sophie was the senior behavioral scientist at WRI at the time of this working paper. She has researched, published and presented extensively on a range of topics including sustainable and healthy diets, physical activity, smoking cessation, and alcohol reduction. Sophie holds a Ph.D. from the University of Cambridge in behavioral science and public health and is a chartered psychologist with the British Psychological Society.
World Resources Institute is a global research organization that turns big ideas into action at the nexus of environment, economic opportunity, and human well-being.

\section{Our Challenge}

Natural resources are at the foundation of economic opportunity and human well-being. But today, we are depleting Earth's resources at rates that are not sustainable, endangering economies and people's lives. People depend on clean water, fertile land, healthy forests, and a stable climate. Livable cities and clean energy are essential for a sustainable planet. We must address these urgent global challenges this decade.

\section{Our Vision}

We envision an equitable and prosperous planet driven by the wise management of natural resources. We aspire to create a world where the actions of government, business, and communities combine to eliminate poverty and sustain the natural environment for all people.

cc) creative (7) Copyright 2021 World Resources Institute. This work is licensed under the Creative Commons Attribution 4.0 International License.

ccommons (i) To view a copy of the license, visit http://creativecommons.org/licenses/by/4.0/ 